Estudios Constitucionales, Año 10, No 1, 2012, pp. 245 - 288.

ISSN 0718-0195

Centro de Estudios Constitucionales de Chile Universidad de Talca

"Estudio sobre el derecho al recurso en el proceso penal"

Carlos del Río Ferretti

\title{
ESTUDIO SOBRE EL DERECHO AL RECURSO EN EL PROCESO PENAL ${ }^{*}$
}

\author{
STUDY ON THE RIGHT OF APPEAL IN CRIMINAL PROCEEDINGS
}

\author{
Carlos del Río Ferretti ${ }^{2 * *}$ \\ Profesor de Derecho Procesal \\ Universidad Católica del Norte \\ cdrio@ucn.cl
}

RESUMEN: Esta investigación examina el derecho al recurso en el proceso penal. En lo sustancial se mantiene que estando el proceso, dentro de una concepción cognoscitivista de jurisdicción, orientado a la correcta aplicación del derecho, el derecho al recurso aparece también como una regla epistemológica que propicia justamente dich a orientación. En segundo término, se perfilan precisamente los contenidosy exigencias normativos especificos que derivan del denominado derecho al recurso y se realiza un cotejo con la regulación legal del recurso de nulidad y su realidad aplicativa, con el propósito de poner en evidencia las inconsistencias normativas y jurisprudenciales con los contenidos comprendidos en aquél.

PALABRAS CLAVE: Jurisdicción, proceso, debido proceso, derecho al recurso, recurso de nulidad.

ABSTRACT: This research examines the rigth of appeal in criminal proceedings. Essentially, it is argued that while the process, in the cognoscitivist conception of jurisdiction, aims at the correct application of law, the rigth to appeal also appears to be a epistemological rule that encourages exactly that. Secondly, it outlines the contents and regulatory requirements from the right of appeal and it includes a comparison with the legal aspects of the motion of vacate and its applicability, with the purpose of showing the regulatory and case law inconsistencies with its content.

KEYWORDS: Jurisdiction, process, due process of law, right of appeal, appeal.

\section{CONSIDERACIONES PRELIMINARES: EL PROCESO COMO INSTRUMENTO PARA}

LA CORRECTA APLICACIÓN DEL DERECHO OBJETIVO Y RECURSOS, EN LA OPCIÓN COGNOSCITIVISTA DE LA JURISDICCIÓN Y DEL PROCESO

Para poder estudiar los recursos procesales siempre habrá necesidad de tomar una posición inicial de enfoque que nos permita dotarle de sentido en el sistema

\footnotetext{
${ }^{1 *}$ El presente estudio es parte del Proyecto fondecyt regular n. 1100865, titulado «El derecho al recurso en el proceso penal: su contenido, eficacia y condicionamientos normativos y jurisprudenciales», actualmente en ejecución y del cual es investigador responsable el autor. Artículo recibido el 14 de septiembre de 2011 y aprobado el 28 de octubre de 2011.

$2^{* *}$ Doctor en Derecho por la Universidad de Valencia. Dirección postal: Larrondo 1281, Campus Guayacán, Universidad Católica del Norte, Coquimbo. Correo electrónico:
} 
procesal entero. Por dicho motivo es que el estudio del tema de los recursos requiere como el que más de una inicial toma de posición sobre qué entendemos por fin del proceso y función de la prueba y cómo éstos se pueden vincular con o -todavía más- influir en los recursos procesales.

La finalidad del proceso o su función institucional es la aplicación del derecho al caso concreto, para lo cual habrá necesidad desde luego de verificar (enjuiciar o establecer) correctamente los hechos jurídicamente relevantes y desde allí formular un juicio jurídico acertado del que se desprenderán las consecuencias jurídicas correspondientes. Son fundamentales entonces la correcta aplicación de la norma y antes el acertado establecimiento de hechos. No basta a nuestro juicio con poner el acento de forma casi exclusiva en que el proceso sea un instrumento para que la jurisdicción haga aplicación del Derecho objetivo al caso concreto, sin advertir en ello lo importante que es apuntar un presupuesto fundamental, cual es que dicha función no sea posible si no se dota a la jurisdicción de los mecanismos adecuados para la correcta verificación o establecimiento de los hechos relevantes para el asunto de que se trate, circunstancia que en último término acaba constituyéndose en una condición necesaria para la función de aplicación, como recalca parte relevante de la doctrina ${ }^{3}$.

Sólo con lo anterior se puede comprender aquello de que el proceso no sea puramente un medio de resolución de conflictos o de solución de controversia, sino que, sin descartar este aspecto, deba caracterizarse por ser un medio para producir la decisión justa del asunto enjuiciado, entendida ésta a lo menos como una decisión que suponga la aplicación correcta del Derecho ${ }^{4}$. Lo apuntado aparece evidente si se admite el carácter cognitivo de la jurisdicción y si se descartan posiciones de escepticismo propias del realismo jurídico que desprecian o niegan eficacia normativa a la norma, con su consecuente escepticismo procesalístico basado en la renuncia o negación ab initio del mencionado carácter propio de la jurisdicción 5 .

\footnotetext{
${ }^{3}$ Vid. Wróblewski (1979), pp. 166-188; y del mismo (1992), p. 131; Ferrajoli (2004) p. 27, y del mismo (1995), pp. 33-45 y 92-93; (2007a), pp. 333 y ss., 695 y ss., y 879-885; (2007b), pp. 71 y ss., 90 y ss., 212 y ss; TARUfFo (2005-a), pp. 167 y ss.; del mismo (2005b), p. 86; (2008), pp. 22 y ss., pp. 109 y ss., 131 y ss., 159 y ss., 172 y ss., 184 y ss., 217 y ss., 221 y ss., 229 y ss., 234 y ss.; (2009), pp. 17-46; SCHÜNEMANN (2002), pp. 290 y ss; GÖssel (2004), pp. 169-190; FerRer (2007), pp. 29-32; GASCÓN (1999), pp. 64 y ss.; Del Río (2008), pp. 157-182, y del mismo (2009), pp. 82 y ss., y 114 y ss.

${ }^{4}$ Vid. WróblewsKi (1979), pp. 166-188; Ferrajoli (2004), p. 27; y del mismo (1995), pp. 33-45 y 92-93; (2007a), pp. 333 y ss., 695 y ss., y 879-885; y (2007b), pp. 71 y ss., 90 y ss., 212 y ss.; TARUFFo (2005a), pp. 167 y ss.; del mismo, (2005b), p. 86; (2008), pp. 22 y ss., pp. 109 y ss., 131 y ss., 159 y ss., 172 y ss., 184 y ss., 217 y ss., 221 y ss., 229 y ss., 234 y ss.; (2009), pp. 17-46; SCHÜNEMANN (2002), pp. 290 y ss.; Ferrer (2007), pp. 29-32; Gascón (2009), pp. 64 y ss.; Del Río (2008), pp. 157-182, y del mismo (2009), pp. 82 y ss., y 114 y ss; Coloma et al. (2009), pp. 303-344; Horvitz (2009), p. 21.
}

5 Ibid. cit. supra. 
En efecto, la jurisdicción posee en un sistema procesal de garantía una función cognitivo-declarativa que se resuelve en que ésta no se colma con cualquiera decisión jurisdiccional ${ }^{6}$, sino que ella impone que deba configurarse como una función a través de la cual se declara que unos hechos que fundan la pretensión procesal han sido probados o no (afirmaciones confirmadas o refutadas), y sobre cuya base se realiza el juicio jurídico con pleno sometimiento a la estricta legalidad, verificando si concurren o no los elementos fácticos taxativamente consignados que colman la norma penal.

Por ello, a partir de este enfoque -en la versión de FERRAJOLI, por ejemplo- se ha formulado una teoría de la garantía jurisdiccional como función esencialmente sometida a la ley (rectius, al Derecho), de naturaleza cognoscitiva, la cual, por lo tanto, se basa en argumentos cognitivos respecto de los hechos y recognitivos acerca del Derecho, y sobre los cuales se funda la declaración jurisdiccional. Por un lado, tal condición de la jurisdicción equivale a configurarla como aplicación sustancial o como afirmación de la ley, y por otro, también se corresponde con el aseguramiento de aquel específico derecho fundamental tutelado por la jurisdicción que es la inmunidad de las personas ante las decisiones arbitrarias. Esta es la concepción esencial de la garantía secundaria en la teoría axiomática del Derecho, en donde estricta legalidad y estricta jurisdiccionalidad se encuentran indisolublemente unidas ${ }^{7}$. También WRÓBLEWSKI ${ }^{8}$, entre otros ${ }^{9}$, ha puesto de relieve a la función jurisdiccional como aplicación de la ley, haciendo a la par hincapié en que ésta depende en una parte importante de la exacta declaración de los hechos (como condición necesaria aunque no suficiente).

Ciertamente, incluso la concepción cognoscitivista concede que el conocimiento judicial se produzca en un contexto institucionalizado como es el proceso ${ }^{10}$. Es así que en la normativización del conocimiento judicial a raíz del contexto institucional que importa el proceso asisten junto a las reglas que garantizan la maximización de la búsqueda de la verdad -llamadas garantías epistemológicas ${ }^{11}-$,

\footnotetext{
${ }^{6}$ Sobre este punto nos hemos pronunciado anteriormente, adhiriendo a la posición cognoscitivista de la jurisdicción (estricta jurisdiccionalidad). Del Río (2009), pp. 126-129.

7 Del Río (2009), p. 128.

${ }^{8}$ Vid. Wróblewski (1979), pp. 113 y ss, y del mismo (1992).

9 Vid. Ferrer (2007), pp. 29-30. También Del Río (2007), pp. 45-57; y del mismo (2009), pp. 49-60.

${ }^{10}$ Circunstancia que marca una diferencia relevante con el conocimiento que se produce en otras áreas de investigación o descubrimiento que no tienen fines prácticos inmediatos. Este punto ha sido puesto de relieve entre nosotros en el interesante estudio de Coloma et al. (2009), pp. 303-344.

${ }^{11}$ Así, GASCÓn (1999), pp. 120-123. También inciden en el argumento esencial FerRer (2007), pp. 35 y ss. WróbleWski (1979), pp. 166-188; Taruffo (2005-b), pp. 357 y ss; TWINING (2006), pp. 192-236. Pero sobre todo mucho antes CALAMANDREI (1945c), pp. 150-151.
} 
un conjunto de otras reglas orientadas a tutelar otros bienes, derechos, intereses o fines prácticos concurrentes, dando lugar a reglas no epistemológicas o contraepistemológicas, que no favorecen o incluso entorpecen o limitan en algunos casos la averiguación de la verdad: así las reglas de exclusión probatoria, la limitación temporal del proceso, la regla de eficacia de cosa juzgada son ejemplos claros de lo indicado ${ }^{12}$.

\section{Medios para la correcta aplicación jurisdiccional del Derecho}

Dado este punto de partida, esto es, la aplicación correcta del Derecho al caso concreto como finalidad del proceso jurisdiccional, se sigue la necesidad de que el mismo deba contemplar todos los medios técnicos adecuados a ese propósito, vale decir, destinados a maximizar lo más posible el cometido funcional del proceso. Por ello nos parece sugerente lo defendido por TARUFFO, cuando sostiene que la orientación del proceso a la obtención de decisiones justas se convierte en una exigencia del proceso justo. Para el autor, y aquí seguramente haya una diferencia sustancial con las posiciones de DAMAŠKA ${ }^{13}$ o FLETCHER $^{14}$, la orientación del proceso a decisiones justas no implica la tendencial exclusión de procesos con garantías procesales o formales. La diferencia con éstos se nota en que no se sostiene una suerte de tensión o exclusión insalvable, en donde más medios para asegurar la justicia de la decisión importe menos garantías formales o, al revés, mientras más garantías menos capacidad del sistema para asegurar decisiones correctas, en la típica interpretación liberal extrema. Para TARUFFO ${ }^{15}$ la clave está en la necesidad

\footnotetext{
${ }^{12}$ Nótese que se suele poner de relieve que el establecimiento de un sistema de impugnaciones ha de ponderar de una parte la necesidad de justicia y de otra la pronta resolución con eficacia de cosa juzgada. Vid. Nuzzo (2008), pp. 1-4.

${ }^{13}$ DАMAŠKA (2000), pp. 154 y ss; 212-213; 233-234; 330-332 y 381-388; y del mismo (2003), pp. 174-178. Bien es verdad que el autor, sobre todo en la primera obra, expone dos formas generales de concebir la justicia: orientada a la resolución de conflictos (típica del laissez faire) o dirigida a la aplicación de políticas (típica del activismo del Estado de Bienestar). Con todo, estas concepciones se combinan con formas y estructuras de los órganos o autoridades judiciales existentes en cada sistema de justicia (formas de ejercicio del "poder judicial"), en las que se distinguirían el poder jerárquico y el paritario. Los modelos procesales concretos surgirían de la combinación de las dos orientaciones generales de los procesos con las dos formas de ejercicio de poder. Es decir, de las combinaciones de procesos como resolución de litigios o aplicación de políticas con las formas de poder jerárquicas o paritarias. En la exposición se realiza un amplio conjunto de matices y precisiones, sin embargo, detrás del discurso construido subyace una lógica de tensión excluyente donde cada variable procesal o forma de poder se mira como opuesta e inversamente proporcional a la otra, lo cual resulta discutible, especialmente por la elección de los modelos opuestos y sus configuraciones.
}

${ }^{14}$ Fletcher (2004), pp. 323-335.

15 TARuffo (2008), pp. 229-249. 
no excluyente de ambas en la noción de «justo proceso», al punto de que éste (el proceso) no se satisface con la pura dimensión "procedural justice» con renuncia a la decisión correcta. Por ese motivo se afirma la necesidad de que el proceso se encuentre orientado a la consecución de la misma, y que dicha sistemática orientación sea una consecuencia o exigencia del proceso justo. De esa manera se explica que la forma jurisdiccional de aplicación del Derecho y especialmente del Derecho penal ${ }^{16}$ sea en sí misma una garantía. Es decir, se explica su condición de tal fundamentalmente porque asegura un grado de juridicidad y racionalidad en la decisión (adjudicación) que no ofrece ninguna otra forma de aplicación del Derecho o medio de resolución de conflictos ${ }^{17}$.

Cuando el análisis arranca desde la exigencia del derecho al recurso incardinado en el debido proceso, y dentro de él en la tutela judicial efectiva, resulta fundamental la consideración precedente, porque añade un excelente argumento teórico a nuestra posición, en el sentido que la existencia de un derecho al recurso aparece naturalmente exigido por el justo proceso en cuanto medio procesal-epistémico dispuesto en el proceso para la obtención de decisiones correctas o justas. En la misma línea, $\mathrm{NuZZO}^{18}$ pone de relieve la relación íntima de la función procesal y los medios de impugnación. De aquí resulta entonces que el recurso es garantía procesal y, al tiempo, regla o garantía epistemológica, esto es, un mecanismo a disposición de las partes para impugnar las resoluciones que les perjudican y, de otra parte, un medio procesal para maximizar las probabilidades de acierto judicial $\mathrm{y}$ de decisiones justas ${ }^{19}$.

Pero todavía con mayor grado de especificidad, se habrá de apuntar que un sistema procesal del carácter enfatizado precedentemente, con un sistema de valoración racional del mérito probatorio, tenderá a prever en su diseño, a su vez,

${ }^{16}$ Vid. Montero (1997), pp. 15-21; Ferrajoli (1995), pp. 33-116 y 537-603, aunque a lo largo de toda la obra subyace la idea de que el garantismo penal descansa en la garantía jurisdiccional. Sin ella se diluyen las demás garantías procesales y sustanciales o de Derecho material. En la misma línea, De CARO (2004), pp. 5 y ss; Ruggiero (2004), pp. 77 y ss; De Rosa (2004), pp. 87 y ss; Cecanese (2004), pp. 146-147; Cappa (2004), pp. 153-173; MarColini (2005), pp. 160-176 y 183-187.

Cabe poner de relieve la crítica que se ha hecho en este sentido a sistemas de negociación penal como el estadounidense. ILLUMiNATI (1988), p. 4, no duda en calificar al sistema de negociación penal estadounidense (que es la forma general de aplicación de la Ley penal en ese país) como un sistema de aplicación de la Ley penal de carácter burocrático-administrativo, el cual en definitiva toma el lugar del sistema jurisdiccional y acusatorio teóricamente consagrado.

17 Vid. Ferrajoli (2007-a), pp. 333 y ss, 695 y ss, y del mismo (2007-b), pp. 71 y ss, 90 y ss, 212 y ss.; (1995) passim.

${ }^{18}$ Nuzzo (2008), p. 3 y pp. 38-39.

19 Calamandrei (1945c), pp. 199 y ss. 
un sistema de recursos eficientes. En este orden de ideas, no es coherente consagrar el carácter racional cognoscitivo del modelo procesal y luego no garantizar adecuadamente dicha naturaleza. Por el contrario, en los modelos de orientación no cognoscitivista, que enfatizan la perspectiva intimista o subjetiva del enjuiciamiento fáctico, como aquel resultado que surge del contacto inmediato del juzgador con la práctica de la prueba, como «fogonazo» de convicción holístico, inverificable e insustituible, irá acompañado de ordinario por un débil sistema de recursos, que prácticamente impida cualquier control sobre el enjuiciamiento con relación al mérito, especialmente probatorio. Nótese como, por ejemplo, Ferrer $^{20}$ aparece apuntando la relación existente entre un sistema de valoración racional de la prueba y la existencia de controles por vía recursiva eficientes, en contraste con los modelos irracionales de valoración o eminentemente persuasivos que en general vienen vinculados con sistemas recursivos muy débiles que en la práctica impiden cualquier control eficaz sobre la racionalidad del juicio fáctico y la forma de valoración de la prueba. Lo dicho se podría formular entonces como la siguiente relación: mientras más racional sea la valoración-motivación más posibilidades de articular controles eficaces sobre la corrección del juicio fáctico y jurídico, y, al contrario, sistemas de prueba orientados a la persuasión (subjetivos) y con valoración intimista e irracional tenderán a favorecer -en la práctica- modelos recursivos débiles o incluso ineficaces.

En la lógica del modelo racional y cognoscitivista de proceso jurisdiccional el recurso no es el medio para sustituir una valoración íntima y subjetiva por otra de la misma naturaleza, sino la vía para verificar la racionalidad del juicio mismo como resultado de la valoración de la prueba ${ }^{21}$ o en el caso del segundo grado (apelación) la forma de sustituir una valoración comprobadamente incorrecta ${ }^{22}$.

\section{El recurso como mecanismo para maximizar las posibilidades de obtención de una sentencia justa (ante el error) y como garantía procesal de parte (ante la insatisfacción subjetiva)}

El enjuiciamiento jurisdiccional, como toda actividad humana, no escapa a la posibilidad de error, que amenaza con frustrar la correcta aplicación del Derecho.

\footnotetext{
${ }^{20}$ Ferrer (2007), pp. 62-66; Gascón (1999), p. 8; y antes Taruffo (2005a), pp. 167-219. Entre nosotros, ACCATino (2009), pp. 347-361; y del mismo (2010), pp. 119-143.

${ }^{21}$ Ibid. cit. supra.

${ }^{22}$ Es evidente que por esta razón la misma existencia de un recurso eficaz retroactúa sobre las fases procesales anteriores, obrando como elemento de potenciación racionalizadora del proceso previo y del enjuiciamiento. Incluso aquello aparece reconocido por TWINING (2006), pp. 220-222.
} 
Tal resulta una realidad inextirpable o insuprimible del todo, pero desde luego ello no significa que el proceso resignadamente no deba contemplar (como toda realidad normativa) los mecanismos que maximicen sus fines (los del proceso) y minimicen las condiciones que atentan o produzcan un decaimiento de aquéllos, pues de esto depende en buena medida que la jurisdicción se resuelva en la aplicación justa del Derecho ${ }^{23}$.

Ciertamente la represión del error judicial materializado en una resolución judicial injusta no es el único fundamento de los medios de impugnación ni opera por sí sólo. Determinados recursos persiguen la uniformidad tendencial de la aplicación del Derecho objetivo junto a la corrección de errores, otros buscan dar tutela a precisas garantías procesales. En este último caso la injusticia material de la resolución no importa, sino que lo relevante es que ella provenga o sea el resultado de un proceso sin garantías. En segundo término, en todos los supuestos, los medios de impugnación operan como mecanismos procesales a disposición de las partes; son éstas las que deben impugnar o resistir la resolución judicial, con lo cual, obviamente, el error judicial no basta para que opere la vía impugnativa o recursiva: se requiere de la insatisfacción subjetiva, es decir, ha de concurrir el denominado fundamento subjetivo ${ }^{24}$.

Aun con matices debe afirmarse, no obstante, la necesidad de considerar al error como un fundamento objetivo del recurso, con lo cual discrepamos de las posiciones que lo han querido desdeñar como irrelevante, dándole énfasis sólo o preferentemente al fundamento subjetivo, queriendo alentar una perspectiva en donde se busca subrayar el carácter de medio a disposición de las partes, lo que por lo demás calza con su condición de garantía procesal: en último término -se sostiene- la interposición del recurso se explica en la insatisfacción subjetiva y por ello -se esgrime- la parte no soporta la carga de demostrar ningún error para recurrir. Efectivamente ello es así, la interposición del recurso viene explicada en la insatisfacción subjetiva de un legitimado, lo cual es una prueba de su condición de garantía procesal. Pero el análisis queda trunco si no se observa al mismo tiempo que lo que hace el recurrente a través de la interposición de un recurso es hacer valer una pretensión impugnativa que únicamente podrá prosperar si efectivamente se comprueba el error fáctico o jurídico o la infracción procesal. Y por eso mismo en su interposición debe esgrimir ordinariamente estas situaciones que justifican la

${ }^{23}$ En ello hay bastante uniformidad en la doctrina procesal más autorizada, vid. CALAMANDREI (1945b), pp. 350 y ss; WACH (2006), pp. 249 y ss; Roxin (2000), pp. 445 y ss.; Ortells (1998), pp. 343-344, y del mismo (2009), p. 485; Montero (2005), p. 406; Nuzzo (2008), p. 20; Di LuCiano (2009), pp. 1-2. En nuestro medio Cortez (2005), pp. 4-10. Se manifiesta en contra Carocca (2000), pp. 310-311.

${ }^{24}$ Vid. Cortez (2005), pp. 6-10. 
necesidad de conocimiento en fase de recurso. La pura insatisfacción y el gravamen (desde una perspectiva subjetiva) no bastan para que el recurso prospere. Es a partir de esta constatación que no se puede negar el fundamento objetivo del recurso $\mathrm{o}$, si se quiere -con más precisión- de la pretensión recursiva. Aquí opera una relación equivalente a la que se da entre acción procesal, como derecho a acceder a la jurisdicción y a una decisión fundada y la pretensión procesal misma, la que para ser estimada requiere que se dé o verifique el fundamento objetivo, como es el conjunto de hechos relevantes deducidos ${ }^{25}$.

Ligado, por otra parte, a todo lo dicho se encuentra el problema epistemológico, referido a si efectivamente las impugnaciones que constituyen una revisio prioris instantiae son un medio adecuado para eliminar errores de juicio o, mejor, para asegurar la justicia de la decisión, reduciendo al mínimo posible las probabilidades de error en la decisión final del proceso. Ciertamente se ha querido atacar a la apelación y a otros recursos análogos desde este punto de vista, argumentando que éstos no constituyen en absoluto medios adecuados, pues el juzgador ad quem o del recurso tiene las mismas probabilidades de error judicial que el de la (primera) instancia o, incluso mayores si se sostiene que la calidad de su conocimiento es peor, atendida la falta de inmediación con las fuentes de prueba ${ }^{26}$.

El argumento anterior tiene importancia, pues la interpretación predominante de la libre valoración en nuestro medio se ha basado en una consideración desmesurada atribuida al principio de inmediación, como si este método de práctica de la prueba fuera además principio o presupuesto para la justa y racional valoración, con lo cual se produce un desplazamiento o traslado de la incidencia del principio desde su estimación como técnica de práctica (formación) de la prueba a su consideración como presupuesto para la valoración, de modo que se concluye que no hay valoración probatoria adecuada por un sujeto u órgano que no haya intervenido inmediatamente en la práctica de la prueba. A partir de allí se vinieron a desprender los argumentos de la soberanía del juicio de valoración y la imposibilidad de revisarla como tal. Por esta vía se transitó hacia la concepción intimista de la valoración. En esa visión desde luego es fundamental la percepción inmediata que sirve a la persuasión que es imposible de expresar e imposible de controlar por un tercero que no haya adquirido la misma persuasión inmediatamente ${ }^{27}$. Dicho esquema concibe al

\footnotetext{
25 Calamandrei (1945c), pp. 202-203.

${ }^{26}$ Argumento que se repite bastante en la doctrina procesal de nuestro entorno, y que tiene una larga data, encontrándose ya formulada aunque con matices de relieve en Wach.

27 Ferrer (2007), pp. 63-64. Entre nosotros, han incidido sobre el punto: Coloma (2005), pp. 5-34, y AcCatino (2009), pp. 347-362, y del mismo (2010), pp. 119-143.
} 
recurso no como un instrumento procesal destinado a asegurar la racionalidad del enjuiciamiento, la corrección de éste como expresión de racionalidad, sino antes bien cual instrumento autoritario típicamente jerárquico (propio de los sistemas autoritarios y jerárquicos, en oposición a los liberales y paritarios), pues se le considera un mecanismo de reemplazo de convicciones subjetivas, las cuales, en razón de su irracionalidad, no son cotejables para distinguir a una como mejor o correcta: simplemente, en esa lógica, por medio del recurso se hace primar la convicción del que tiene más jerarquía ${ }^{28}$, pero que supuestamente se encuentra en una posición epistemológica de menor calidad para conocer y pronunciarse respecto del resultado probatorio, justamente porque no ha intervenido con inmediación en la práctica de la prueba, conociendo de la práctica en principio por la vía de registros.

Las cosas, sin embargo, no son de esta manera, sino bien distintas ${ }^{29}$. En efecto, hay varios motivos para afirmar la necesidad de auténtica racionalidad en la valoración probatoria y, sobre todo, para sostener la legitimidad de una revisio prioris instantiae en razón de la superioridad de la posición epistemológica del juzgador ad quem respecto del a quo, en contra de lo que se supone. Primero, aquél cuenta o podría contar con más información objetiva que el de primer grado, lo cual hace aumentar las posibilidades de exactitud de la decisión. Así, si nos hallamos en un sistema de segunda instancia, ello supone por regla general las posibilidades de aportación de nuevas pruebas, incluso en las modalidades restrictivas de revisio prioris instantiae, y también la aportación de hechos desconocidos o de hechos nuevos.

En segundo lugar, no sólo eso, el juzgador ad quem cuenta además con la misma decisión del juzgador a quo, de modo que no resuelve ex novo, como ha debido hacerlo el juzgador de (primera) instancia, sino a partir de todo el material de la (primera) instancia, más el material fáctico y probatorio nuevo eventualmente introducido en (segunda) instancia, y contando ya con la primera decisión e, incluso, pudiendo contar además con la opinión disidente que contrasta con la de mayoría en caso de un tribunal colegiado de primera instancia. Estos elementos incrementan el acervo a partir del cual se formulará el segundo juicio (o el control recursivo), concediendo una posición epistemológica al juzgador ad quem sustancialmente superior respecto del de primera. En efecto, cualquiera que haya intervenido en un proceso de toma de decisiones sabe que el que resuelve o se pronuncia al final, después que otros, y conociendo los pronunciamientos anteriores, tiene más posibilidades de acierto, pues su análisis arranca de un punto en donde

${ }^{28}$ DAMAŠKA (2000), pp. 212-213; y del mismo (2003), pp. 174-178. En contra GASCÓN (1999), p. 8.

29 Para la correcta comprensión vale partir considerando a WACH (2006), pp. 257-258. 
se han anticipado perspectivas de análisis, reflexiones jurídicas, enjuiciamientos valorativos sobre la prueba y en donde se ha propuesto una solución o, incluso, más de una posible.

En tercer término, además hay que considerar los argumentos basados en la mayor experiencia y en la más alta formación de los jueces superiores o de segundo grado, generalmente más experimentados y formados que los de primera instancia, elementos que también inciden en las posibilidades de acierto.

Consecuentemente, a nuestro juicio, es erróneo afirmar sin más que el juez de única o primera instancia tiene un conocimiento de mejor calidad y una mejor posición epistemológica -gracias a la inmediación-que el juzgador de segunda instancia (o ad quem $)^{30}$. Se trata de una simplificación nociva que ha enraizado en nuestro medio, con perniciosas consecuencias.

\section{Derecho al RECURSO EN El PROCESO PENAL CHILENO}

\section{Bases normativas del derecho al recurso}

Existe una amplia coincidencia en nuestro medio ${ }^{31}$ sobre el derecho al recurso y su incardinación normativa en la Constitución como parte del debido proceso o del justo y racional procedimiento. En el constitucionalismo chileno hubo prácticamente desde la gestación normativa de la Constitución en adelante una opinión más o menos pacífica en orden a considerar el derecho al recurso un elemento integrador del debido proceso, que en definitiva fue recogido en el art. 19.3 inc. $5^{\circ} \mathrm{CPR}$. El desarrollo de este elemento del debido proceso, que ya aparece mencionado expresamente por la $\mathrm{CENC}^{32}$, no obstante, se limitaba a su pura enunciación, lo que no estaba acompañado con un desarrollo técnico o dogmático relevante. Tal situación se mantuvo invariable por un tiempo, hasta que en el año 1989 se reforma la Constitución y con ello se introduce el art. 5 inc. $2^{\circ}$ de la CPR en su actual redacción, con el cual se sanciona explícitamente el carácter supra legal de los tratados internacionales sobre derechos humanos ratificados por Chile y vigentes. El constitucionalismo chileno comienza a hablar del bloque de constitucionalidad, integrado por la Constitución y por las dichas normas internacionales, que pasan a hacer parte del ordenamiento constitucional.

\footnotetext{
${ }^{30} \mathrm{Al}$ respecto consultar las clarividentes palabras de CALAMANDReI (1945c), p. 203.

31 Vid. en el constitucionalismo Silva (2002), pp. 76-78; Evans (2004), pp. 142-144; Fernández (2006), pp. 49-85; Nogueira (2007), pp. 9-16 y 19 y ss.; y en el procesalismo, puede consultarse CarocCa (2000), pp. 311-312; Bordalí (2003), p. 258; Tavolari (2005), pp. 393 y ss; Cortez (2005), pp. 17 y ss.; Duce y Riego (2007), pp. 508-509; HoRvitz (2009), pp. 9-25.

32 Vid. SiLVA (2002), pp. 76-78; Evans (2004), pp. 142-144.
} 
A partir de allí se pueden vislumbrar nuevos respaldos normativos de rango supra legal para el derecho al recurso en cuanto contenido del debido proceso. En términos generales las normas internacionales dotaron de un contenido explícito y más preciso a la cláusula constitucional del debido proceso $^{33}$, que en lo tocante al derecho al recurso hay que referir a los arts. 14.5 PIDCP y 8.2 letra h) CADH. Estas dos normas lo reconocen de manera explícita y, por lo tanto, nadie puede dudar que esté perfectamente configurado como garantía.

A nivel legal el derecho al recurso no recibe en nuestro ordenamiento un explícito reconocimiento, aunque existen normas en el CPP que permiten sostener la armónica recepción de las garantías procesales en general. Así, el art. 10 se refiere a la denominada cautela de garantía, en donde expresamente se le reconoce eficacia directa a las "garantías judiciales» de la Constitución y los tratados internacionales, aunque el precepto tenga el defecto de que aparezca declarando aquello sólo a favor del imputado. El art. $4^{\circ}$ se refiere a su turno a la presunción de inocencia y, concretamente, al trato de inocencia. Dice que «Ninguna persona será considerada culpable ni tratada como tal en tanto no fuere condenada por una sentencia firme», poniendo de relieve que la presunción cede sólo ante la irrevocabilidad de la decisión de condena, a la que se arriba únicamente en el momento de la firmeza. Tal declaración parte del supuesto que el proceso se ha de estructurar sobre la base de la existencia de recursos contra la sentencia definitiva, de modo que la presunción se deba predicar incluso respecto de ella (de la sentencia definitiva), en el entendido que el imputado aun condenado puede todavía obstaculizar el directo efecto de irrevocabilidad de la sentencia a través de un recurso en su contra, lo cual además enlaza muy bien con la defensa y las garantías procesales reconocidas al imputado en el art. $7^{\circ} \mathrm{del}$ CPP, desde la primera actuación y a lo largo de todo el proceso penal, hasta la completa ejecución de la sentencia (imputado-condenado), con lo cual todas esas garantías - las de la Constitución incluidas- son acervo jurídico del imputado durante todas las fases del procedimiento, alcanzando entonces al debido proceso y en él al derecho al recurso.

\footnotetext{
${ }^{33}$ No ignoramos que una línea jurisprudencial del Tribunal Constitucional ha puesto en el último tiempo una inquietante nota de incertidumbre acerca de la cuestión incluso en sus bases, al pronunciarse sobre un aspecto determinado del derecho al recurso a propósito de la inaplicabilidad del art. 387 inciso segundo CPP, hipótesis en la cual ha vertido ciertos argumentos jurídicos que prima facie podrían parecer negadores del derecho al recurso como contenido de rango constitucional o incluido en el debido proceso, aunque el mismo Tribunal, vislumbrando las posibles consecuencias negativas que podrían derivarse de los mismos, se ha apresurado a precisar que se trata de pronunciamientos de control concreto de constitucionalidad, insinuando con ello que en un control abstracto de la norma legal con el precepto constitucional el resultado podría ser otro, vale decir, la posible tacha de inconstitucionalidad del precepto. Vid STC de 30 de enero de 2008, rol 986-2007; STC de 1 de abril de 2008, rol 821-07-INA; STC de 7 de octubre de 2008, Rol No 1.130-07-INA.
} 


\section{Qué significa el derecho al recurso}

Aun con todo lo dicho, la unanimidad sobre la existencia del derecho al recurso y su incardinación constitucional en el debido proceso (o justo y racional procedimiento) en buena medida resulta sólo una coincidencia inicial, es decir, en el punto de partida del análisis. Pero desde allí en adelante la convergencia de opiniones tiende a diluirse. En efecto, al revisar la doctrina y la jurisprudencia se advierte que existe una gran dispersión de conceptos sobre lo que se comprendería -desde el punto de vista jurídico estricto- en el derecho al recurso. Por lo anterior es oportuno atender al estudio de su contenido o contenidos, cuestión que nos permitirá hacer el enfoque más exacto del problema fundamental, cual es la correspondencia más o menos (in)satisfactoria de la articulación legal del sistema de recursos penales y de su realidad aplicativa con los requerimientos normativos derivados del reconocimiento del derecho al recurso.

Creemos que una visión integral del problema necesita de un escrutinio que distinga partes distintas en la totalidad de la cuestión, las que funcionarían como variables dentro del análisis. En primer lugar resulta fundamental la determinación jurídica de lo que sea el derecho al recurso en el proceso penal y los contenidos del mismo. Y, en segundo lugar, la confrontación de aquello con la articulación legal concreta del recurso de nulidad, para hacer patentes cuáles son las cuestiones de la regulación que son insatisfactorias y en qué medida, y cuáles los déficits claramente delimitados en la realidad aplicativa.

$\mathrm{Al}$ analizar el soporte constitucional de la garantía del debido proceso y el desarrollo interpretativo de los arts. 14.5 PIDCP y 8.2 CADH, se observa que existe base para considerar que el contenido del derecho al recurso es complejo, en el sentido que se integran en él varios contenidos específicos o aspectos, que sumados permiten su completa configuración normativa. Un primer pronunciamiento interpretativo en este sentido aparece en la jurisprudencia del Comité de derechos humanos de la ONU, que en el Dictamen de 20 de junio de 2000 (caso Gómez Vásquez c. España, 701/1996), afirma que el derecho al recurso del art. 14.5 PIDCP se satisface con una revisión integral del fallo recurrido, de modo que el recurso previsto en la legislación interna -con independencia de la denominación que adopte- debe entonces permitir un entero o integral examen de la sentencia de fondo, con lo cual, de manera implícita se comienza a sostener lo que denominamos un contenido complejo del derecho al recurso, pues de algún modo puede mantenerse que éste se descompone en aspectos distintos, puesto que de allí se colige que ya no es suficiente la sola existencia de uno o más recursos contra la sentencia de fondo, sino que se exige o añade la exigencia de un específico tipo de examen: la revisión integral o completa de 
lo resuelto. Lo anterior aparece refrendado posteriormente en la jurisprudencia del mismo Comité de derechos humanos de la ONU en el Dictamen de 30 de julio de 2003 (en caso Joseph Semey c. España), en Dictamen de 7 de agosto de 2003 (en caso Sineiro Fernández c. España, 1007/2001), en Dictamen de 1 de noviembre de 2004 (en caso Alba Cabriada c. España), y en Dictamen de 29 de marzo de 2005 (en caso Martínez Fernández c. España).

En el ámbito de la CADH, la opinión más nítida de la Corte Interamericana en esta línea es la contenida en la Sentencia de 2 de julio de 2004 (en caso Herrera Ulloa vs. Costa Rica), en la que aparece explícitamente recogiendo la doctrina del Comité de derechos humanos de la ONU, pero aun con más precisión que en ésta. Se expresa y afirma que el derecho al recurso del art. 8.2 letra h) implica que "La posibilidad de 'recurrir el fallo' debe ser accesible, sin requerir mayores complejidades que tornen ilusorio este derecho" (n. 164), y luego, por separado, dispone que "Independientemente de la denominación que se le dé al recurso existente para recurrir un fallo, lo importante es que dicho recurso garantice un examen integral de la decisión recurrida". También establece el mismo criterio, aunque de manera menos patente, la Sentencia de la Corte Interamericana de Derechos Humanos, de 30 de mayo de 1999 (en caso Castillo Petruzzi y otros v/s Perú).

Con base en estos antecedentes creemos que resulta necesaria la distinción de aspectos diversos que integran un contenido complejo del derecho al recurso. Existe base bastante clara en la citada jurisprudencia y en los textos de los tratados internacionales consignados para distinguir y separar el acceso al recurso del examen integral (como tipo de examen) con sus respectivos significados y precisas consecuencias. Pero todavía nos parece que junto con estos dos contenidos se deba añadir de manera inevitable un tercer aspecto como es la calidad del examen jurisdiccional que se abre con la fase de recurso, el cual debe reunir unas características bien distintivas, que son necesarias para no ver frustrados en buena medida la misma esencia del derecho al recurso.

Será este el esquema de análisis del contenido del derecho al recurso que aplicaremos en las páginas que siguen.

\section{ANÁLISIS DE LOS ASPECTOS DEL DERECHO AL RECURSO}

El derecho al recurso puede ser definido como el reconocimiento a las partes e intervinientes de la titularidad de la facultad o poder para impugnar las sentencias de fondo (y resoluciones equivalentes) que le agravian, a través de un recurso que permita la revisión del enjuiciamiento de primer grado y asegure un conocimiento adecuado o correspondiente a su objeto. 
Tal cual hemos anticipado, es menester distinguir dentro del derecho al recurso los siguientes aspectos ${ }^{34}$ : (1) primero, el derecho de acceso al mismo, (2) segundo, la necesidad de un tipo de examen específico, y (3) tercero, la calidad del conocimiento y decisión del recurso como manifestación de tutela jurisdiccional. El tratamiento separado y diferenciado permitirá identificar un contenido y eficacia jurídicos científicamente delimitables para cada uno de ellos, circunstancia que clarifica y precisa la amplitud de las materias incluidas en la totalidad del objeto de análisis, sin quedarnos entrampados en las parcelas del problema, confundiendo la parte por el todo, o confundiendo argumentos que hacen a una parte del objeto y que se utilizan con referencia al todo.

\section{El acceso al recurso: pro actionis o favor impugnationis}

El contenido primario del derecho al recurso es el acceso al mismo, el cual se vincula a la existencia legal de recursos y a la facilidad de acceso, cuestión que se ha de valorar en varios aspectos de la regulación del sistema recursivo. Este contenido tiene inmediata relación con la forma de concebir el sistema de recursos, el cual debe estar a disposición de las partes e intervinientes a los que se les reconoce el derecho a valerse de los mismos para impugnar las resoluciones agraviantes.

Ciertamente el acceso a los recursos en nuestro sistema -como en la mayoría de países de nuestro entorno jurídico-es materia de configuración legal, de modo que el legislador puede imponer unos presupuestos y requisitos para el ejercicio del derecho, pero al mismo tiempo ello no ha de importar la introducción de formas (formalismos) y condiciones que hagan ilusorio o gravoso lo que se reconoce inicialmente como garantía. De otro modo la configuración sería el medio para proceder al vaciamiento de la misma, privándole de cualquier eficacia siquiera condicionante. Desde luego, ello importa una condición de respeto en su esencia para el legislador, pero también proyecta su eficacia condicionante a la realidad aplicativa e interpretativa. Consecuentemente, en la realidad aplicativa, es decir, en la jurisprudencia, se debería tener muy en cuenta este punto de partida sobre todo en la verificación de estas cuestiones a través de los denominados controles de admisibilidad que les corresponde aplicar a los órganos jurisdiccionales.

a) La cuestión del régimen de presupuestos y requisitos del recurso y del respectivo control-aplicación judicial

En primer término, el asunto implica lo que la doctrina suele denominar cuestiones de recurribilidad objetiva y cuestiones de recurribilidad subjetiva. Las

${ }^{34}$ Vid. Fernández (2005), pp. 145-169; Nogueira (2007), pp. 104-118, que al analizar la jurisprudencia del sistema interamericano de justicia, vislumbra en ella esta cuestión. 
primeras apuntan a la determinación de las resoluciones y contenidos susceptibles de ser impugnados a través de un recurso determinado (resoluciones recurribles). Las segundas son aquellas referidas a qué sujetos tienen el poder o el derecho de impugnar a través de un recurso determinado una resolución (lo que suele denominarse legitimación). Tanto unas como otras son primer objeto de un régimen de acceso al recurso y determinan en términos absolutos la entrada al mismo, de modo que si una resolución no es recurrible por un recurso ella simple y llanamente no queda sometida a esa impugnación. Algo análogo acontece con la recurribilidad subjetiva, de manera que si un sujeto procesal no está legitimado no puede en absoluto recurrir. Pero esto que parece una obviedad no permite, sin embargo, el razonamiento contrario sensu, de suerte que se pueda concluir que el recurso sea en las hipótesis contrarias siempre admisible. Es decir, son presupuestos necesarios, pero no suficientes. Aparte se requerirá del interés procesal (otro presupuesto), y además que la concreta interposición se realice con los requisitos legales. Aun, con todo, tan importante como el régimen normativo de presupuestos y requisitos -en cuanto determinación normativa del acceso al recurso- es el sistema de control-aplicación judicial de entrada (control de admisibilidad del recurso), el cual en la práctica acaba declarando la concurrencia de los presupuestos y requisitos necesarios para acceder a la fase de recursos. El acceso al recurso entonces posee dos aspectos bien nítidos y diferenciables complementarios: de una parte, las determinaciones normativas y, de otra, las cuestiones de aplicación o de control de admisibilidad judicial.

Cabe precisar respecto de lo normativo que el establecimiento de presupuestos y requisitos procesales de los recursos es una cuestión propia de configuración legal y en principio el mismo establecimiento de ellos no importa infracción al derecho a recurrir y, por lo tanto, es perfectamente posible que el legislador establezca unas limitaciones, condiciones y formas de hacer valer los recursos por los intervinientes procesales, lo cual en sí mismo no se insinúa contrario al acceso a los recursos. Pero lo anterior es plausible en la medida que ésta sea una configuración que tenga un sentido o función que se justifique en el contexto procesal en que se aplica y no importe una limitación esencial que reduzca a su mínima expresión el acceso al recurso o que infrinja principios esenciales del proceso como el de igualdad de partes o que introduzca formalismos enervantes dispuestos para la exclusión de la oportunidad recursiva o su gravosa o compleja utilización ${ }^{35}$.

El derecho al recurso supondrá que en la ley procesal se contemple la existencia de normas para impugnar las resoluciones que causen agravio a las partes (e inter-

35 Justamente este tipo de consideraciones ha supuesto el unánime rechazo -en la dogmática y las legislaciones- de la reforma en perjuicio del recurrente. Vid. Roxin (2000), pp. 454-455; LópEZ (2007), pp. 9-18; BARRIENTOS (2007), pp. 175-207, aunque con importantes matices tocantes a su amplitud. 
vinientes) y especialmente para atacar la sentencia de fondo, pero junto con ello se tiene que poner énfasis en el acceso mismo a los medios de impugnación puesto que no cabe duda, a nuestro juicio, que el derecho al recurso implicará ante todo una articulación legal del recurso y una aplicación jurisprudencial que tiendan a la potenciación y facilitación del acceso, y no al revés, lo que, precisamente, viene exigido por el derecho al recurso en su contenido de acceso al mismo. En el derecho comparado la fuerza dada al acceso al recurso -en casos paradigmáticos como el italiano ${ }^{36}$ - encuentra amplia recepción en el propio sistema de recursos penales, a través de diversas normas y mecanismos procesales. Así, en primer lugar, se concibe como disposición general la regla de conversión de los medios de impugnación del art. 568.5 CPPi, que hace prevalecer la voluntad del impugnante por sobre la calificación jurídica formal del medio que se emplea, lo que permite sostener la amplísima eficacia normativa del principio acuñado en ese sistema del favor impugnationis, que marca y distingue toda la aplicación de las reglas de acceso a los medios de impugnación legalmente establecidos.

Añade la misma norma, por otra parte, que la impugnación interpuesta ante juez incompetente -en lugar de provocar la declaración de inadmisibilidad- se resuelve con el deber del juez de remitirla al juez competente ${ }^{37}$. Se regula también en el modelo italiano, la situación concreta de conversión del recurso de casación en apelación en la hipótesis de varias impugnaciones distintas (casaciones y apelaciones por distintos recurrentes) en contra de una misma resolución, caso que se resuelve con la conversión de las impugnaciones de casación en apelaciones y no, desde luego, con la declaración de inadmisibilidad de aquellas (arts. 569.2 y 580 CPPi) ${ }^{38}$.

Por último, se cierra el círculo normativo que garantiza el acceso al recurso con la norma que dispone la taxatividad de la inadmisibilidad, de modo que ésta no se puede declarar sino por las causales expresamente previstas por el legislador, la cual también es parte de las reglas generales de los medios de impugnación (art. $591 \mathrm{CPPi})^{39}$.

Otro tanto, en esa línea, puede observarse en la doctrina del TC español que al interpretar el derecho al recurso y la garantía de la tutela judicial con relación al régimen de recursos de la LECrim ha dicho desde luego que el derecho al recurso importa necesariamente el acceso a los medios de impugnación legalmente

\footnotetext{
${ }^{36}$ Vid. Tonini (2007), pp. 711-724; Santalucia (2008), pp. 51-55; De Roberto (2008), pp. 55-75, 155 160 y 225-228; FolLIERI (2008), pp. 509-510.

37 Vid. Santalucia (2008), pp. 51-55.

38 Vid. De Roberto (2008), pp. 55-75, 155-160 y 225-228.

39 Vid. De Roberto (2008), pp. 225-228.
} 
previstos por la ley. En la doctrina constitucional se ha recalcado que es legítimo que el legislador establezca presupuestos y requisitos procesales para el acceso al recurso, pero que ello no puede suponer un formalismo enervante que haga problemático o difícil el acceso a los previstos legalmente, regla que necesariamente debe proyectarse a su aplicación jurisprudencial. La conclusión precedente se ha basado en la consideración de que esta garantía es manifestación del principio pro actione, que rige también en fase de recurso ${ }^{40}$.

La jurisprudencia internacional, tal como observamos anteriormente, distingue el acceso al recurso como contenido específico del derecho al recurso, con un contenido distinto del tipo de conocimiento o examen que se exige al recurso ${ }^{41}$. Particularmente interesante es la detallada sentencia de la Corte Interamericana de Derechos Humanos en Sentencia de 2 de julio de 2004, caso Herrera Ulloa $v / s$ Costa Rica, en donde a nuestro juicio se hace la separación claramente entre ambos aspectos. En las consideraciones de la Corte, en los apartados 140 a 167 se realiza una amplia exposición sobre la materia y en varios pasajes se hace la distinción anotada, la cual además queda expresada en el apartado 164 de manera clara cuando señala: "La posibilidad de 'recurrir del fallo' debe ser accesible, sin requerir mayores complejidades que tornen ilusorio el derecho". En esa misma línea suele citarse el caso Castillo Petruzzi y otros v/s Perú, Sentencia de la Corte Interamericana de Derechos Humanos, de 30 de mayo de 1999.

El acceso al recurso en suma tiene interés, ya que de él deriva la consecuencia de la necesidad normativo-legal de la existencia de medios de impugnación contra las resoluciones penales y en especial de aquellas de fondo. Junto con esto además exige a nivel normativo las previsiones y disposiciones que faciliten verdaderamente el acceso a los mismos, de manera que ello importará una regulación que potencie el uso expedito, y rechazará la configuración legal de medios de impugnación formalista que desincentiven su utilización por su dificultad de acceso. En el nivel jurisprudencial el acceso al recurso se expresará, sobre todo, en la necesaria aplicación de los mecanismos de admisibilidad con una interpretación favorable al acceso al medio de impugnación, debiendo hacer primar la voluntad de impugnación por sobre exigencias técnicas o formales que embaracen su ejercicio. La inadmisibilidad al ser la negación de acceso de un derecho en principio ampliamente reconocido debe estar estrictamente motivada, pues ha de ser ésta la de derecho estricto, y no, al revés, el acceso, como a menudo afirma la jurisprudencia.

${ }^{40}$ Vid. por todos, Ortells (1998), pp. 343-344; TAPia (2005), pp. 1093-1104; Calderón (2005), pp. 161182.

${ }^{41}$ Vid. NogueIra (2007), pp. 104-118. 
Veamos hipótesis específicas de infracción al acceso al recurso como contenido del derecho al recurso en la regulación nacional.

\section{b) Primer problema de recurribilidad objetiva}

La perplejidad normativa ha venido producida, en primer lugar, por el presupuesto más básico de todos, cual es la determinación de las resoluciones impugnables y sus contenidos susceptibles de impugnación. La lacónica norma del CPP que hace referencia a la sentencia definitiva sin más, sin advertir que dentro de ella pueden existir contenidos-decisiones que no son los que típicamente se consideran esenciales, tales como los que se refieren a los beneficios alternativos a la pena o las $\operatorname{costas}^{42}$, ha generado el problema respecto de la posibilidad de atacar estas decisiones comprendidas en la sentencia definitiva. La jurisprudencia -últimamente Sentencias Corte Suprema, Rol No 2.055-2008, de 26 de mayo de 2008 y Rol No 1.239-09, de 25 de marzo de 2009- y la doctrina se han pronunciado por la desestimación de la posibilidad de recurrir en contra de estos contenidos de la sentencia, pues aun cuando se hallen contemplados en ella en realidad no forman parte de la misma en cuanto su naturaleza jurídica no sería la de sentencia definitiva (resolución que resuelve el asunto controvertido), afirmación que se hace con base en la denominada tesis de la desintegración o disgregación de la sentencia definitiva. Este criterio resulta discutible, pues el problema es más complejo de lo que parece, sobre todo si se atiende a la evidente estrechez del sistema recursivo chileno, lo cual en la práctica dejaría a un conjunto de decisiones judiciales importantes en la esfera del arbitrio judicial sin control de juridicidad de ninguna especie.

En efecto, la jurisprudencia no ha advertido que el actual sistema procesal no sólo sea de única instancia, sino además de recurso único contra la sentencia definitiva, lo cual significa que ésta, en principio, es impugnable sólo a través del recurso de nulidad, a salvo el recurso de queja, medio excepcional y atípico. Antes, en cambio, la sentencia definitiva era impugnable por apelación y también por casación forma y fondo. De ese modo, la resolución que desestimaba el otorgamiento de un beneficio aun cuando no accedía a la casación si era apelable, como de hecho expresamente estaba consagrado en el art. 25 de la Ley No 18.216, circunstancia que reducía considerablemente el problema. En otras palabras la teoría de la disgregación o desintegración de la sentencia negaba acceso a la casación, pero no al derecho al recurso, el cual se satisfacía a través del acceso a la apelación, conforme aseguraba el art. 25 Ley No 18.216.

No obstante, con el nuevo sistema procesal la apelación no procede contra sentencia definitiva dictada por el Tribunal de Juicio Oral: esta posibilidad queda bloqueada entonces para la decisión sobre beneficios allí contenida, aunque el art.

42 Cortez (2007), pp. 59-62. 
25 de la Ley No 1.8216 no fuera inicialmente modificado sobre ese extremo, circunstancia que generaba una clara antinomia de textos: de una parte, la regla general que convertía en inapelables las sentencias de los Tribunales de Juicio Oral y de otra una norma particular como la del art. 25 de la Ley No 18.216 que aparecía consignando la apelabilidad de la denegatoria de beneficios alternativos. Tal contraste normativo no fue advertido sino hasta bien entrado en vigor el nuevo proceso. Sólo con posterioridad y con la finalidad de armonizar un sinnúmero de contradicciones legales, se decidió dictar la Ley No 19.806, denominada Normas Adecuatorias. En ella se contempló el artículo 11 que modificaba el art. 25 de la Ley No 18.216, suprimiendo la posibilidad de recurrir de apelación contra la denegatoria de beneficios alternativos. Pues bien, es en este contexto normativo en que resulta particularmente nociva la teoría de la disgregación de la sentencia. En efecto, ocluida la apelación y quedando únicamente el recurso de nulidad como medio para impugnar la sentencia definitiva, dicha teoría supone avalar la completa inatacabilidad de la decisión sobre los denominados beneficios alternativos a la pena contenida en la sentencia definitiva, desconociendo para esta decisión de fondo el derecho al recurso, cosa que hasta antes de la reforma procesal penal no sucedía, aun sosteniendo la discutible doctrina de la disgregación, pues incluso en esa hipótesis pervivía la posibilidad de apelar al amparo del artículo 25 de la Ley No 18.216.

Tales cuestiones constituyen problemas jurídico-positivos y jurisprudenciales vinculados al acceso al recurso, el cual actualmente está iluminado por ciertos criterios desarrollados en la dogmática avanzada y en el Derecho positivo moderno, como los denominados pro actionis y favor impugnationis. La jurisprudencia chilena ha puesto en duda estos principios, aplicando criterios rigurosísimos de admisibilidad ${ }^{43}$ que cierran o restringen al máximo el acceso al recurso ${ }^{44}$. Pero, probablemente aquí no sólo nos hallemos con un problema de interpretación, sino además y en cierta medida con un problema de ineficacia de los principios dentro de nuestro modelo procesal. La norma no ha establecido, con respecto al acceso al recurso, prácticamente ninguna garantía normativa eficaz, lo cual desde luego es un déficit normativo ${ }^{45}$.

\footnotetext{
${ }^{43}$ Vid., entre muchas, Sentencia Corte Suprema, Rol No 267-2006, 15 de febrero de 2006, Identificador Legal Publishing 33808; Sentencia Corte Suprema, Rol No 6.583-2006, de 30 de enero de 2007; Sentencia Corte Suprema, Rol No 1.304, de 8 de abril de 2008, LegalPublishing No 38720; Sentencia Corte Suprema, Rol No 2.055-2008, de 26 de mayo de 2008, LegalPublishing No 39049; Sentencia Corte Apelaciones de Temuco, Rol No 1.113-2008, de 17 de noviembre de 2008.

${ }^{44}$ Sobre los problemas jurisprudenciales en el control de admisibilidad, vid. CORTEZ (2007), pp. 53 y ss.; FERNÁNDEZ (2008), pp. 92 y ss.

${ }^{45}$ Los argumentos aquí consignados aparecen con más precisión en nuestra disidencia en Sentencia Corte de Apelaciones de La Serena, Rol No 203-2011, de 24 de agosto de 2011.
} 
Con todo, si la norma que determina las resoluciones recurribles puede carecer de la precisión deseable en la determinación de contenidos recurribles, probablemente no sea el normativo el problema esencial al respecto, sino antes bien el restrictivo control de acceso de nuestra jurisprudencia. Un ejemplo puede ser justamente el de la "teoría de la desintegración", que no parece conciliar con el derecho de acceso al recurso. Tal es así que la CA de Antofagasta con la misma norma (imprecisa si se quiere) ha llegado a la solución correcta que demandamos, en Sentencia Rol No 103-2008 de 11 de junio de 2008, y en Sentencia Rol No 274-2008 de 17 de diciembre de 2008.

\section{c) Segundo problema de recurribilidad objetiva}

Una segunda cuestión que plantea graves problemas desde el punto de vista del acceso al recurso es la actual inexistencia del recurso mismo para impugnar la sentencia dictada en el nuevo juicio tras la anulación de una primera sentencia (art. 387 inciso $2^{\circ} \mathrm{CPP}$ ), situación que ya ha sido denunciada, justo es decirlo, por nuestra doctrina. Así por ejemplo TAVOLARI ${ }^{46}$, LOPEZ ${ }^{47}$, CORTEZ $^{48}$ y HORVITZ ${ }^{49}$. Piénsese que con la disposición en vigor se niega el acceso al recurso de la segunda sentencia como regla general, salvo que la segunda sentencia sea de condena y la primera (anulada) hubiese sido absolutoria. Y en esa simplificación extrema de los problemas jurídicos complejos, se olvida el legislador que no sólo se le quedaba atrás el caso en que se pasa de absolutoria a otra sentencia absolutoria -situación en que la negación del recurso aun cuando criticable no parece escandalosa- sino además el caso de que se pase de condenatoria a otra condenatoria, incluso con posibilidad de ser más grave la segunda que la primera anulada, en cuyo supuesto la condena (más grave incluso) con la norma simplificadora tampoco tiene acceso a recurso alguno.

Lamentablemente la jurisprudencia del Tribunal Constitucional ha incidido en el punto con una orientación en sentido aparentemente contrario, cuando se ha tenido que pronunciar con ocasión de varios requerimientos de inaplicabilidad de la norma, casos en los cuales ha atendido a circunstancias fácticas de cada situación sub lite, hecho que en lugar de aclarar el punto lo ha convertido en algo confuso ${ }^{50}$.

46 Tavolari (2005), pp.407-408.

${ }^{47}$ López (2005), pp. 445-447.

48 Cortez (2006), pp. 411-413.

49 Horvitz (2009), pp. 9-25.

50 Vid. Tribunal Constitucional, Rol No 986-2007, de 30 de enero de 2008; Tribunal Constitucional, Rol No 821-07-INA, de 1 de abril de 2008; Tribunal Constitucional, Rol No 1.130-07-INA, de 7 de octubre de 2008 . 


\section{d) Problemas de recurribilidad subjetiva}

Respecto a la recurribilidad subjetiva también se observa algún problema de relieve en relación con el acceso al recurso, así, por ejemplo, la falta de garantía adecuada de la legitimación del imputado, esto es, del acceso directo del imputado como legitimado independiente y separado del defensor técnico. La cuestión de la legitimación del imputado, plantea una dificultad referida a la eficacia del precepto que la establece en el art. $352 \mathrm{CPP}$ en términos generales. En efecto, cabe preguntarse si tal legitimación reconocida in genere $-\mathrm{y}$ tal vez sin mucha conciencia de lo que significaba-, cobra o no vigor dentro de la regulación del recurso de nulidad y de los demás recursos, o si ella guarda correspondencia con el resto de la regulación y con los requisitos de interposición de los recursos, o si se disponen o no de mecanismos efectivos para asegurar la adecuada expresión de la voluntad impugnativa del imputado, sobre todo cuando ésta no es compartida por el defensor, que, a menudo, ni siquiera es de confianza, o cuando se expresan simultáneamente y por separado las voluntades impugnativas del defensor y del imputado y difieren en contenido. Lamentablemente estas interrogantes esenciales no se han formulado y contestado con vigor en la práctica.

También ha sido problema de esta especie el tocante a la legitimación del Ministerio Público para recurrir por la infracción de garantías procesales, y específicamente por la del debido proceso. El punto generó dudas en la doctrina, incluso con precisas opiniones en orden a esgrimir la falta de legitimación del Ministerio Público ${ }^{51}$, mientras que otra parte de aquélla mantuvo la posición contraria.

La primera opinión que negaba legitimación activa al MP para recurrir por infracción de garantías procesales (y específicamente del debido proceso) se sostenía en la misma naturaleza y origen político de éstas, enfatizando que habían surgido para la tutela de los particulares frente al poder estatal, y que en consecuencia, teniendo en cuenta este origen (y sentido de ellas) las garantías procesales en esta lógica son una limitación al poder estatal y por esta vía al poder punitivo del Estado. Desde este punto de vista -afirman sus sostenedores- resulta inadecuado que se le permita esgrimir al MP la infracción de una garantía de la que él no puede ser titular, y permitirle al Estado - por intermedio de aquél- beneficiarse o aprovecharse de una infracción que él mismo ha producido. En esa línea se sostenía que el MP era co-detentador de la potestad punitiva del Estado y que dada esa calidad no podía al tiempo esgrimir la garantía del debido proceso en su favor,

51 Carocca (2003), p. 265; López (2005), pp. 404-411; DuCE y Riego (2007), pp. 523 y ss; Rieutord (2007), pp. 28-42. 
argumento que incluso quedó plasmado de ese modo en la minoría disidente de la jurisprudencia de la Corte Suprema ${ }^{52}$.

La posición opuesta ${ }^{53}$, partidaria de la legitimación del MP en los mismos términos que las demás partes e intervinientes, se sirve, en primer lugar, de una razón normativa expresa, como es la existencia de la norma general del art. 352 CPP que no hace distinción de ninguna especie por medio de la imposición de límites de recurribilidad subjetiva.

En segundo término, se ha puesto de relieve que aquella regla de igualdad normativa encaja bien en un sistema procesal acusatorio que reconoce la igualdad procesal de las partes, todo lo cual, por otra parte, se opone al establecimiento de privilegios procesales a favor de una de las partes y en perjuicio de otra a través del despojo de una oportunidad procesal o de la limitación de posibilidades de aprovechamiento de éstas.

En tercer término se ha apuntado ${ }^{54}$ que no cabe confundir la función de parte del MP con la de titularidad y ejercicio del ius puniendi (poder de castigo) que siempre está depositado de forma exclusiva y excluyente en el juzgador penal (el único que puede imponer un castigo, art. $\left.1^{\circ} \mathrm{CPP}\right)$. El MP concurre al proceso como parte formal, en una estructura procesal triádica-actus trium personarum-, en el cual se deben asegurar oportunidades y medios parejos ${ }^{55}$ equivalentes para las partes, lo que se presenta además como una característica derivada de la simétrica morfología del proceso penal.

En fin, cabría añadir que el argumento de la titularidad subjetiva de las garantías procesales, que por su origen y naturaleza no podría corresponderle al MP en tanto órgano estatal, olvida que detrás de las garantías procesales como tales habrá una norma o principio procesal con valor objetivo, en cuanto dispone la necesidad de que el proceso se desarrolle de conformidad a ciertas formas vinculadas a la estructura y principios fundamentales que ordenan el proceso penal y que resulta menester preservar. A ese proceso, con esas formas y con esos principios todos los intervinientes pueden y deben acceder: hay interés objetivo en ello. En otro caso, se podría dar el absurdo jurídico de llegar a consentir procesos en donde se lesiona el principio de contradicción o se desconocen oportunidades de prueba o

\footnotetext{
52 Vid. opinión de minoría en estos fallos: Sentencia Corte Suprema, Rol No 3.984-05, de 15 de noviembre de 2005; Sentencia Corte Suprema, Rol No 1.300-07, de 22 de mayo de 2007, y Sentencia Corte Suprema, Rol No 3.003-10, de 12 de julio de 2010.

53 Pereira (2005), pp. 41-46; Tavolari (2005), pp. 260-269; Cortez (2006), pp. 66-78; Fernández (2008), pp. 107-108.

${ }^{54}$ CORTEZ (2006), pp. 74 y ss.

55 Vid. supra.
} 
de alegación o donde se infrinjan derechos determinados, con tal que todas estas situaciones no se concreten en lesiones a los intereses procesales del imputado, sino de los demás intervinientes y particularmente del MP.

La jurisprudencia de la CS inicialmente contradictoria y dubitativa ${ }^{56}$ parece haberse alineado al fin con la tesis que concede legitimación activa al MP, la que en definitiva nos parece la correcta. Así cabe concluir a la luz de la Sentencia Corte Suprema, Rol No 3.984-05, de 15 de noviembre de 2005 57; Sentencia Corte Suprema, Rol No 4.656-05, de 30 de noviembre de 200558; Sentencia Corte Suprema, Rol No 1.300-07, de 22 de mayo de 200759, y Sentencia Corte Suprema, Rol No 3.003-10, de 12 de julio de 2010, en las que se recogen en sustancia los argumentos dados a favor de la legitimación.

\section{Tipo o naturaleza del examen recursivo: revisio prioris instantiae}

El derecho al recurso no sólo importa acceso a un recurso en los términos explicados. Lo anterior es relevante, pues se sostuvo por algunos que el derecho respectivo se satisfacía con el acceso simplemente ${ }^{60}$. El punto además es decisivo si se tiene en cuenta que aquello entroncó en nuestro medio con la discusión de si el derecho al recurso en materia penal exigía la necesidad de consagrar la apelación contra la sentencia definitiva. Es bien conocido el debate que se inició con ocasión de la discusión y tramitación legislativa del Proyecto de Código Procesal Penal, que propuso la eliminación del segundo grado con la supresión de la apelación y el establecimiento en su lugar de un recurso de naturaleza esencialmente casacional. La discusión, como era natural, se centró en si aquello satisfacía el derecho al recurso como contenido del debido proceso, que aparecía complementado por los arts. 14.5 PIDCP y 8.2 CADH. La opinión dominante sostenía que el derecho al recurso no exigía un recurso precisamente de apelación; los tratados internacionales no demandaban esto, sino la existencia de un medio de impugnación contra la sentencia y, específicamente, contra la condenatoria.

Paralelamente se esgrimía que la eliminación del doble grado de jurisdicción, al que se calificaba de típico control vertical, quedaba cabalmente compensado por

\footnotetext{
56 Acerca de las contradicciones y dudas iniciales sobre el punto en la jurisprudencia de la CS, Vid., por todos, Cortez (2006), pp. 66-73.

57 Sentencia Corte Suprema, Rol No 3.984-05, de 15 de noviembre de 2005, LegalPublishing, No 33196.

58 Sentencia Corte Suprema, Rol No 4.656-05, de 30 de noviembre de 2005, LegalPublishing, No 33244.

59 Sentencia Corte Suprema, Rol No 1.300-07, de 22 de mayo de 2007, LegalPublishing, No 36478.

60 Vid. Carocca (2000), pp. 311-312; Tavolari (2005), p. 395.
} 
la introducción de los controles horizontales y específicamente por el establecimiento del carácter colegiado del juzgador de mérito (argumentos que sometemos a crítica más adelante). En este sentido, una parte de nuestra doctrina ha querido -sobre todo con ocasión de la elaboración del CPP- vislumbrar en los recursos un mecanismo de control inquisitivo o autoritario de justicia que se correspondería poco con un sistema de justicia acusatorio moderno. Tales posiciones encontraron algún abono teórico en las esquematizaciones contrastantes de Derecho comparado $^{61}$, como forma de propalación de un sistema de justicia «acusatorio» («más puramente acusatorio» y por eso más garantista: obviamente, una simplificación) u otras veces hallaba respaldo en visiones que dentro de nuestra tradición jurídica intentaban explicaciones eminentemente histórico-políticas de los recursos procesales $^{62}$. En ambas perspectivas los medios de impugnación (y especialmente la apelación) no asegurarían una mejor administración de justicia sino en realidad no serían otra cosa que mecanismos que el poder del Estado posee para asegurar un control jerárquico de los jueces, constituidos en un conjunto de funcionarios que intervienen en la implementación de políticas ${ }^{63}$. El sistema de recursos como especie de control vertical y jerárquico sería un rasgo muy acusado de los sistemas de justicia inquisitivos y completamente ajenos a los acusatorios modernos.

A este respecto se solía utilizar el argumento del origen histórico de la apelación, haciéndola entroncar -con un grado importante de imprecisión- con el absolutismo: y de allí se hacía derivar una muestra más, ahora histórica, de la superación de la apelación y, por esa vía, de los denominados controles jerárquicos o verticales. Sin embargo, en nuestra opinión, el análisis omitía datos fundamentales ${ }^{64}$.

Pero más allá de los argumentos esgrimidos con más o menos propiedad, la requerida revisión integra de la sentencia que parece ser el giro o expresión al uso en la jurisprudencia internacional para la interpretación de los arts. 14.5 PIDCP y

\footnotetext{
${ }^{61}$ DAMAŠKA (2000), pp. 212-213; y del mismo (2003), pp. 174-178.

${ }^{62}$ Vid. en esta línea las observaciones de MAIER (1989), pp. 210 y ss., y 510 y ss.

${ }^{63}$ Vid. Carocca (2000), pp. 300 y ss; Duce y Riego (2007), pp. 503-505; López (2005), pp. 347 y ss.

${ }^{64}$ La explicación del origen de la apelación no se halla en la simplificadora mimetización del absolutismo y el sistema inquisitivo como la misma cosa, uno en lo político y otro en lo judicial. Desde luego el absolutismo como manifestación política tiene una trayectoria propia que no es exactamente la del sistema judicial inquisitivo. Y nótese, además, que esa idea de que la apelación se justificaba como herramienta de control absolutista de los jueces sometidos al monarca es incorrecta por parcial e imprecisa. La apelación efectivamente cumplió una función política en el régimen absolutista, pero no arranca allí su historia ni termina allí su justificación. En efecto, en el sistema inquisitivo (que no es lo mismo que absolutismo político) la apelación tenía una función judicial distinta, tal como han puesto de relieve con agudeza ciertos juristas: cual species defensionis reequilibrador de las escasas posibilidades de defensa que poseía el imputado en el juicio de primer grado, al punto de que fuera calificado de praesidium innocentiae (esto es, reducto protector de la inocencia). Nuzzo (2008), pp. 34-35, y también Bonnet (2000), p. 859.
} 
8.2 CADH, y que apunta indubitadamente a la naturaleza (amplitud) del examen para entender satisfecho el derecho al recurso en esta específica faceta, puso en evidencia el punctum dolens de la reforma al sistema de recurso que se estableció con el Código Procesal Penal, el cual podría ser puesto del siguiente modo: aun cuando sea cierto que los tratados internacionales no se refieran -ni puedan hacerlo-a la apelación o al doble grado de jurisdicción, sí exigen la revisión ante un tribunal superior, lo cual ha dado pie para que se vaya consolidando una interpretación de que ello exige una revisión integral, como hemos dicho, y no meramente formal o acotada a determinados aspectos jurídicos ${ }^{65}$.

¿Cómo se ha querido enfrentar esta cuestión? Probablemente la única línea argumental que se ha hecho cargo de esto en defensa del diseño legal actualmente en vigor, es aquella que ha considerado que el criterio normativo antes indicado no se satisface con el "doble grado" (apelación), sino con una cosa distinta que en nuestro medio se le ha denominado "doble conforme", cual especie de control recursivo indeterminado, que en todo caso sería algo menos que la apelación, pero algo más que la casación.

Con base en este orden de ideas la doctrina chilena mayoritaria ${ }^{66-67}$ sostuvo que el «doble grado» estaba superado en los modelos acusatorios y entonces al momento de interpretar el derecho al recurso de los arts. 14.5 PIDCP y 8.2 letra h) $\mathrm{CADH}$ consideró simplemente que en lugar de éste, el derecho a un recurso se vinculaba con lo que se vino a denominar la "doble conforme" o "doble conformidad"68, como una especie bien imprecisa de control recursivo, en todo caso, limitado a la infracción de las garantías procesales y a la incorrecta aplicación del Derecho material.

Es así como en nuestro medio, López ${ }^{69}$ defiende -como derecho al recurso- un tipo de examen distinto del doble grado, pero que al mismo tiempo -se deduce de su argumentación-sería más intenso que el propio y clásico de naturaleza casacional. En el punto sigue de cerca la posición de Maier a quien refiere como fuente. Incluso

\footnotetext{
${ }^{65}$ PASTOR (2001), pp. 89-112, quien sugiere ideas semejantes.

${ }^{66}$ Carocca (2000 y 2003); Tavolari (2005); López (2005); Duce y Riego (2007).

67 La posición contraria fue expresada en lo sustancial por el profesor PereIRA (1999), pp. 15-21, quien intervino además por el informe presentado ante la Comisión de Constitución, Legislación, Justicia y Reglamento del Senado, Segundo Informe de la misma, Sesión 5a, Legislatura 342, de 20 de junio de 2000. En este el autor insistía en la necesidad de mantener el doble grado de jurisdicción, lo cual aparecía como exigencia a raíz de los tratados y pactos referidos a la materia, los que en su opinión exigían la consagración de un recurso ordinario en contra de la sentencia de fondo, de modo que en la práctica no se podía satisfacer éste con la introducción de un recurso extraordinario o de derecho estricto que sólo abría estrechos márgenes de revisión de la sentencia de instancia, limitados a aspectos jurídicos.
}

68 Vid. Tavolari (2005), pp. 393 y ss; López (2005), pp. 359-360.

${ }^{69}$ López (2005), pp. 350 y ss. 
pone una cita del argentino, que a nuestro juicio no se presenta muy claramente perfilada, generando más dudas técnicas. López dice que la doble conformidad se identifica con "'el derecho a lograr un nuevo juicio' cuando 'mediante el recurso se comprueba que la condena, por fallas jurídicas en el procedimiento, en la percepción directa de los elementos de prueba por parte del tribunal que la dictó o, incluso, por fallas en la solución jurídica del caso, no puede ser confirmada como intachable y, por ende, no se sostiene frente al recurso'. La doble conformidad supone, entonces, que la condena debe ser capaz de subsistir el reexamen en un nuevo juicio, si se cumplen los requisitos que habilitan la revisión". Y en seguida, el autor -ahora respecto del recurso de nulidad-apunta que es un recurso "amplio" y "sin restricciones de acceso provenientes de un excesivo formalismo" y que "permite en términos generales la invalidación del juicio oral y la sentencia cuando existe una infracción sustancial de derechos o garantías constitucionales referida a las formalidades del juicio o a los hechos que se hubieren dado por probados, permitiendo la revisión del respeto a los límites a la valoración de la prueba impuestos por las reglas de la sana crítica”.

Sin embargo, todas estas vueltas argumentales no atacan el punto fundamental para saber exactamente qué es lo que denominan-Maier y López- el examen de doble conformidad. El nudo es el siguiente: o la doble conformidad es un control sobre la motivación del juicio fáctico, de modo que se resuelve en un escrutinio sobre la corrección de ésta como justificación de la resolución (cosa ampliamente discutida como ponen de relieve estudiosos de la materia ${ }^{70}$ ), o la doble conformidad es derechamente un control sobre la fijación de los hechos, verificando la corrección de ésta según la prueba practicada, para lo cual se requiere no sólo el examen de la motivación como pura justificación, sino además la contrastación de la declaración de mérito fáctico con la misma práctica de la prueba. En el primer caso, estamos en el esquema de la casación penal tal como es hoy considerada en muchos ordenamientos de nuestro entorno. En el segundo caso, estamos frente al segundo grado de mérito - al menos en la versión de la revisio prioris instantiae-, y no se ve necesidad alguna de llamarle de otra manera ${ }^{71}$.

\footnotetext{
${ }^{70}$ Ferrua (1992), pp. 89-90, y SCHÜNemann (2005), pp. 94 y 98, casi en los mismos términos a propósito de la concepción de sus respectivas casaciones (italiana y alemana), cuando señalan que el control casacional limitado a los vicios de motivación que se desprenden del mismo texto de la resolución impugnada, sin el cotejo de ésta con los resultados de la prueba practicada, lleva en realidad a un control extremadamente superficial que más que verificar la corrección de la motivación se limitan a controlar la sagacidad argumentativa del redactor (Ferrua) o la capacidad jurídica o el pensamiento lógico de este (Schünemann). En suma, no se controla en realidad la motivación, cual justificación de la decisión a la luz de la práctica de los medios de prueba, es decir, del mérito del proceso.

${ }^{71}$ Salvo que, como PASTOR (2001), pp. 119-219, se crea en una casación entendida como recurso ordinario, que incluso abre un segundo grado de jurisdicción en sentido propio.
} 
Desde el punto de vista del examen es hoy indiscutido que no es suficiente cualquier recurso para entender satisfecho el derecho a este. En otras palabras, el acceso a un recurso no basta; se requiere además que sea vía adecuada para un examen íntegro del juicio de primer grado. Respecto de esto no es conveniente la utilización de un concepto como la doble conformidad, cuando se le quiere configurar como una especie de examen impreciso y/o menos intenso que el dado en un segundo grado de mérito: el derecho al recurso ha de poseer un contenido normativo claro que signifique la apertura de una revisión suficiente de la sentencia impugnada o recurrida, necesario para asegurar su eficacia, típicamente de mérito (y no de legitimidad), el cual debe alcanzar la revisión del juicio de hecho como tal, es decir, a la luz de la práctica de la prueba. De lo contrario el derecho al mismo se convierte en una posibilidad de obtener una revisión formal, muy parcial, acotada a los aspectos jurídicos sustantivos o procesales, sin permitir en la práctica ningún control efectivo sobre la parte medular del juicio jurisdiccional, como es el juicio fáctico ${ }^{72}$.

Determinada doctrina nacional ha ido inclinándose, aunque con matices relevantes, en esta dirección en el último tiempo ${ }^{73}$, circunstancia que a nuestro juicio se ha visto propiciada o influida por la insatisfactoria experiencia aplicativa del CPP chileno y respaldada por determinada jurisprudencia y doctrina comparada ${ }^{74}$.

\footnotetext{
72 Vid. Fernández (2005), pp. 145-169.

73 Vid. Fernández (2005), pp. 145-169, y del mismo (2006), pp. 289-315; CorTeZ (2006), pp. 289-315; Nogueira (2007), pp. 104-109, y HorVITZ (2009), pp. 9-25.

$74 \mathrm{Al}$ respecto cabe considerar las observaciones de Schünemann (2005), pp. 86-87, sobre la necesidad de segunda instancia que demandaría la existencia de tratados y pactos que aseguran el derecho al recurso. De especial interés por lo novedoso y amplio de su argumento es el que se refiere a la necesidad de que el asunto sea resuelto por un tercero imparcial. Desde esta perspectiva apunta que el juicio de primera instancia no es en realidad una decisión de una controversia «sino en su origen una afectación a los derechos del ciudadano, contra la que el ciudadano debería poder recurrir a un ulterior juez como tercero imparcial». Para el autor la sentencia de primera instancia (de condena) constituye la "primera afectación material definitiva a la posición del inculpado».

El autor citado además ha precisado que para cumplir con el derecho al recurso asegurado en los tratados internacionales así como con una correcta interpretación constitucional, de la que derivaría la necesidad de crear una segunda instancia con control eficiente del juicio de hecho, no es suficiente el recurso de casación alemán (pp. 94-95).

Montero (1997), pp. 165 y ss., mantiene una opinión divergente respecto del contenido normativo del art. 14.5 PIDCP, especialmente por el origen del precepto y por la diversidad de tradiciones jurídicas que se pueden encontrar entre los países firmantes del pacto. Especial interés tiene el argumento de que en la tradición anglosajona y, especialmente, angloamericana, que influyen fuertemente en estas normas internacionales no haya segunda instancia o segundo grado de jurisdicción tal como lo entendemos en la tradición continental. Mal podía entonces un pacto fuertemente imbuido de dicha tradición exigir algo que no existe exactamente en un grupo relevante de legislaciones nacionales.
} 
3. Dos precisiones fundamentales sobre argumentos dados en nuestro medio para respaldar la opción legislativa de eliminación del doble grado

a) Sobre el argumento de la colegialidad como compensación de la supresión del doble grado de jurisdicción: una opción técnica discutible

Con el propósito de justificar la opción legislativa de supresión del doble grado en nuestro medio se acudió al tradicional argumento de que aquello quedaba perfectamente compensado con el establecimiento de la colegialidad de la instancia de mérito. Lo cierto es que el carácter colegiado del juzgador de (primera) instancia resulta innegablemente un medio procesal destinado a minimizar las posibilidades de error judicial, lo cual por lo demás tiene ya justificación teórica en autores como CALAMANDREI ${ }^{75}$, cuando recalca que la colegialidad resulta un control que se resuelve en un mecanismo que evita -preventivo- el surgimiento del error judicial a través de una exigencia de concurrencia sincrónica de varias voluntades de una pluralidad de jueces a la adopción de una decisión, lo que obra como fiscalización simultánea de las varias voluntades que componen el colegio de jueces y con anterioridad a la adopción de la decisión. Vale decir, resulta un medio que se resuelve en un control preventivo porque opera con anterioridad al surgimiento del error que tiene por objeto evitar, y es control simultáneo o sincrónico, porque la necesidad de concurrencia de varias voluntades de una pluralidad de jueces actúa como una fiscalización cruzada entre esas voluntades al mismo tiempo en la adopción de la resolución.

En cambio, los recursos en general y la apelación en particular (doble grado) son medios represivos del error judicial, que, por lo tanto, operan una vez que este se ha producido, teniendo por objeto su eliminación (y no su evitación). Como es natural, al ser los recursos (y la apelación, específicamente) controles represivos, se constituyen además como controles sucesivos o posteriores al surgimiento del error en una decisión judicial, estando destinados a operar cuando el error, incluso con las prevenciones adoptadas por la ley procesal para evitarlo, no obstante, se verifica.

Con lo anterior, se comprende entonces porqué no parece atendible el argumento de que la supresión del segundo grado quede perfectamente compensada por la naturaleza colegiada del tribunal: lo cierto es que aun con este habrá de tenerse un mecanismo procesal adecuado para eliminar los errores que aun con ello se produzcan en las resoluciones judiciales ${ }^{76}$.

\footnotetext{
75 Calamandrei (1945c), pp. 201-203.

${ }^{76}$ Es así como lo ha comprendido CAlAmandrei (1945c), pp. 201-203, que parte del supuesto de la necesaria combinación del medio preventivo y simultáneo de la colegialidad y del medio represivo y sucesivo del doble grado.
} 
b) La impropiedad de la utilización del argumento de la doble conformidad: significa otra cosa. La necesidad de una apelación limitada (revisio prioris instantiae)

El otro argumento esgrimido en respaldo al diseño del sistema de recursos del CPP, es aquel de la doble conformidad representado en el recurso de nulidad, como una especie de control o examen más o menos indeterminado, más leve que el doble grado, pero más intenso o amplio que la casación: abarcaría una revisión del enjuiciamiento jurídico con el examen de errores in iudicando in iure, además del examen de errores in procedendo y de infracciones de garantías procesales, con lo cual -se alega- tendría la suficiente amplitud para estimar satisfecho el derecho al recurso.

Con todo, y a pesar de lo argumentado en nuestro medio, su contenido técnico-procesal no es el señalado, sino uno bien distinto. La doble conformidad como regla-principio tiene una larguísima trayectoria en la historia de la legislación procesal, siempre con relación al acceso a un recurso determinado de específicas resoluciones (recurribilidad objetiva), que por regla general se ubican después de la segunda instancia. Así, generalmente la doble conformidad impedía el acceso a la tercera instancia, cuando en los dos grados precedentes la decisión era en un mismo sentido ${ }^{77}$. Hasta el día de hoy la regla significada en la doble conformidad se vincula al acceso al recurso que viene con posterioridad a la segunda instancia o con el problema de una condena dictada en única instancia ${ }^{78}$. Tal cuestión entonces ha dado lugar a discusiones sobre recurribilidad objetiva referidas a si todas las sentencias definitivas deben o no estar sometidas a los mismos recursos, y además a cuestiones relativas a la configuración de los poderes de decisión del tribunal ad quem, lo cual se traduce en definitiva en la forma que viene dispuesta la apelación, ya como un juicio puramente rescindente, ya cual juicio rescisorio. Pero lo anterior está bien lejos de como se ha querido presentar en nuestro medio,

77 Calamandrei (1945a), pp. 247 y ss; y del mismo (1945b), pp. 199 y ss y 301 y ss. El principio de la «doble sentencia conforme» está recogido en el Derecho estatutario y de allí pasa a las leyes italianas de los distintos Estados italianos, lo mismo que al derecho germánico. Con todo, observa el autor que a veces la regla que limitaba la apelación o impugnación ante la instancia judicial superior exigía la triple sentencia conforme, en caso de que aparte de la tercera instancia hubiese una ulterior posibilidad de súplica u otra impugnación o revisión. El autor citado (1945a, pp. 247 y ss) da variados ejemplos de cómo funciona la regla o principio de doble o triple sentencia conforme como límite a la apelabilidad de la sentencia o impugnabilidad de ésta.

78 En efecto, al respecto RicCIO (2008), pp. I-XIII, apunta varias ideas muy importantes al respecto. Un primer punto de interés es el que se refiere al concepto de «doppia conforme» que parece derivarse del mismo concepto de regulación del PIDCP, art. 14.5, que se referiría a la revisión de la sentencia de condena, con lo cual habría que considerar este enfoque en oposición a la concepción tradicional de la apelación en iguales términos abiertas para impugnar sentencias de absolución o de condena. Es decir, incide sobre la recurribilidad objetiva. Vid. Nuzzo (2008), pp. 34-43. 
como asunto que se refiera a una suerte de naturaleza jurídica diversa de examen de impugnación, representado por el recurso de nulidad, como tertium genus, diverso del doble grado (revisio prioris instanstiae) y de la casación (control de legitimidad).

El equívoco argumental está en que la «doble conformidad» en nuestro medio se ha utilizado impropiamente con un sentido negativo, para excluir la apelación en términos absolutos, $y$, al mismo tiempo, positivo, para justificar un control recursivo puramente de legitimidad o extraordinario, incluso limitando la legitimación al imputado (recurribilidad subjetiva), cuando no son estos los aspectos que quedan en realidad bajo la esfera de su eficacia. En otras palabras, se le ha utilizado como argumento para excluir el doble grado y para justificar un examen restringido propio de los recursos extraordinarios, esgrimiéndolo como argumento sobre la naturaleza del recurso que determinaría la intensidad del examen, y, de otra, para limitar la recurribilidad subjetiva solamente al imputado, cuando ello no parece aceptable, y justamente distorsiona el problema, que se resuelve mejor desde una perspectiva de recurribilidad objetiva. Lamentablemente con estas utilizaciones desenfocadas no se ha advertido que en el sistema chileno la regla general sea justamente la infracción a la "doble conformidad", precisamente porque en nuestro sistema la sentencia de condena en instancia no puede ser revisada íntegramente, a lo cual debe sumarse la norma del inciso $2^{\circ}$ del art. 387 que cubre un espectro no despreciable de casos prácticos.

La «doble conformidad» en definitiva supone una cuestión de política judicial en la configuración del proceso que requiere de una precisión técnica elemental. En efecto, así si se admite la apelación de la sentencia absolutoria, tenemos dos posibilidades: o el juez ad quem tiene poderes puramente rescindentes y no de reforma o puede acabar dictando -en un segundo enjuiciamiento- una condena, la primera y respecto de la cual no procederá un medio de impugnación que permita la revisión íntegra, con infracción entonces de la "doble conformidad», salvo que se establezca un control efectivo sobre esa condena, cuestión que parece excesiva, y que atentaría contra las posibilidades materiales del Estado y la efectiva articulación de la garantía a un enjuiciamiento en un plazo razonable. Es en ese contexto que no parece atendible asegurar la apelabilidad o recurribilidad en los mismos términos para la absolución que para la condena. Pero eso, como se ve, no tiene que ver con una negación de la apelación ni siquiera en términos parciales, muchos menos en términos absolutos.

Lo dicho, por otra parte, no debe considerarse el aval para el establecimiento de un sistema de impugnación que ponga al MP en una situación procesal disminuida o asimétrica, en donde se pueda romper con el principio de igualdad procesal, privándosele del poder de apelar o recurrir las resoluciones impugnables. 
En cuanto a la apelabilidad subjetiva habría de mantenerse en lo sustancial la paridad procesal.

En efecto, el problema se soluciona satisfactoriamente interviniendo en la apelabilidad o recurribilidad objetiva, y no en la subjetiva. De ese modo para satisfacer la "doble conformidad» y mantener en lo sustancial la paridad o igualdad procesal, se puede zanjar el problema diferenciando los poderes de resolución que el juzgador ad quem posea según el tipo de resolución impugnada: de ese modo respecto de las sentencias de condena se les pueden conferir poderes de enmienda, y tocante a las absolutorias concederles poderes rescindentes y sólo excepcionalmente de enmienda en los casos de que la impugnación se articule en motivos jurídicos y no de enjuiciamiento fáctico.

Desde una perspectiva de lege ferenda, la apelación limitada -si se opta por ella en consideración a que constituye una efectiva revisio prioris instantiae- para ser funcional al sistema procesal debería combinarse con algunas características de la acción de impugnación (recurso extraordinario), exigiéndose así que se recurriese señalando motivos precisos, que a su vez limitasen el conocimiento del Tribunal ad quem ${ }^{79}$.

Por otra parte, con el propósito de asegurar el fiel cumplimiento a la regla de doble conformidad que aparece asegurada por el art. 14.5 PIDCP, habría que distinguir el tipo de juicio y resolución a que debiera de dar lugar la apelación limitada según el tipo de sentencia recurrida: si se trata de una sentencia absolutoria, la apelación aun cuando permita revisar el resultado probatorio no dará lugar sino a un juicio rescindente, que habría de traducirse -en caso de estimación del recurso- en la anulación del juicio y de la sentencia. Desde luego la nueva sentencia, sea absolutoria o condenatoria, debería ser impugnable normalmente.

Para el caso de la apelación de la sentencia de condena el juicio habría de ser directamente rescisorio (sustitutorio) o de reforma.

Es evidente que una apelación concebida de esta forma tiene puntos de contacto con ciertas variantes de casación ampliada ${ }^{80}$, pero posee respecto de ésta la innegable ventaja técnica y práctica, de esclarecer completamente que el recurso sí permite una revisión del mérito fáctico como ponderación del mismo, aunque acotado por el motivo de la impugnación deducida ${ }^{81}$, con lo cual se supera de una vez el insoluble problema de cuáles aspectos del juicio fáctico se pueden controlar, y cuáles no, con un recurso de legitimidad. Y se supera además el problema de las

79 Vid. Montero (1997), pp. 165-186; Calderón (2005), pp. 85-159; SCHÜNemann (2005), pp. 84-99; Nuzzo (2008) pp. 32 y ss.

${ }^{80}$ PASTOR (2001), pp. 119-219.

${ }^{81}$ Tal como lo ha puesto de relieve NAPPI (1992), pp. 119-127. 
confusiones permanentes de la jurisprudencia y los extravíos de la doctrina que no terminan de ponerse de acuerdo ni tan siquiera en lo básico (cada cual con su teoría y explicación).

\section{La calidad del conocimiento que debe poseer la fase procesal a la que se accede con el recurso}

El tercer contenido del derecho al recurso como medio por el cual se accede al examen de lo resuelto en instancia consiste en la necesaria calidad de dicho conocimiento, el cual ha de poseer las cualidades distintivas de la jurisdicción. A nuestro juicio este es un tema al que se ha de atender de manera especial, pues creemos que el mismo fluye naturalmente del derecho al recurso, revistiendo mucha importancia práctica.

Desde una perspectiva normativa cabe sostener que la fase de recursos debe asegurar todas las condiciones para que el conocimiento cumpla con las características esenciales de la jurisdicción que potencien el derecho al mismo, y ello no se convierta en un rito carente de las formas que aseguran las garantías fundamentales del proceso en esa fase procesal: (a) conocimiento oportuno de la pretensión recursiva de la contraparte, (b) oportunidad para preparar y hacer las alegaciones y contrapretensiones procedentes, y, sobre todo, (c) la propia decisión del recurso ha de ser el resultado de un conocimiento suficiente, pues se debe resolver con conocimiento de causa, lo cual debe traducirse y comprobarse además en una adecuada motivación de los fallos ${ }^{82}$.

A nuestro juicio en los dos últimos aspectos mencionados el sistema de recursos muestra determinadas imperfecciones.

a) El problema de la calidad del conocimiento-decisión del juzgador ad quem

El problema de la calidad de conocimiento-decisión del juzgador ad quem estriba en la índole de las resoluciones que se pronuncian en fase de recurso. Con especial fuerza se han mostrado las cuestiones que tocan a la escasa o insuficiente motivación tanto en control de admisibilidad como de fondo, lo cual reviste especial cuidado atendida la práctica ausencia de controles jurisdiccionales efectivos sobre estas cuestiones que permitan a las partes articular alguna denuncia efectiva ${ }^{83}$. Con lo cual además de recursos de vías estrechas se tienen que soportar resoluciones de baja calidad cognitiva e inmotivadas.

Es práctica generalizada en nuestro medio que los motivos para una inadmisión o desestimación de un recurso se reduzcan a unas escuetas líneas en donde

${ }^{82}$ Nogueira (2007), pp. 67-69.

${ }^{83}$ Vid. Ferrajoli (1992), pp. 29-41. 
sólo se consignan las causas sin dar explicaciones sobre qué motivos o justificaciones jurídicas sostienen la decisión de la causa que se esgrime. En esos casos simple y llanamente no hay motivación, pues ésta existe cuando se expresan los razonamientos que justifican la decisión. La motivación ha sido confundida en la aplicación jurisprudencial de recursos con la mera expresión de causa. Esta última es simplemente la consignación de autoridad de una conclusión argumental, pero omitiendo las razones que la respaldan: una suerte de motivación apodíctica, como dice $\mathrm{NAPPI}^{84}$. La mera expresión de causa como consignación de autoridad no es propia de la actividad jurisdiccional que se caracteriza por su carácter cognitivo. Esto es lo que acontece cuando se dice que se inadmite porque falta tal o cual requisito o se desestima porque las circunstancias denunciadas en el recurso no suponen infracción de tal o cual garantía, o que éstas son una cosa distinta de lo que pretende el recurrente, sin decir una palabra sobre lo que sería en su concepto una infracción a una garantía o sin expresar -ni positiva ni negativamente- la acertada interpretación de las mismas o la precisión de sus contenidos, tal como los entiende el tribunal ad quem. Simplemente estas meras expresiones de causa dejan en la sombra los motivos y permiten cohonestar infinidad de razones detrás de los escuetos términos de redacción.

Pero no sólo la inexistencia de la motivación lesiona el carácter jurisdiccional que ha de poseer el conocimiento en fase de recurso. A veces la motivación aparece de modo indirecto, a través de lo que se ha dado en denominar, por la dogmática comparada, la motivación per relationem, que es utilizada por los tribunales superiores de justicia que resuelven sobre la base de la misma motivación de la resolución impugnada, haciendo remisión a ella, con lo cual la resolución que se pronuncia acerca de la impugnación no contiene una motivación propia, autónoma de la de la sentencia impugnada. La cuestión tiene para el caso del Derecho chileno y la praxis jurisprudencial ribetes críticos, pues es ampliamente conocido el uso excesivo de esta técnica de motivación por parte de los tribunales superiores de justicia chilenos, la que, bien es cierto, podría consentirse siempre en la medida que se den ciertas condiciones de legitimidad.

En el Derecho italiano, FOLLIER ${ }^{85}$ ha explicado del siguiente modo el fenómeno: «La motivación per relationem, que se tiene cuando, en el justificar determinada resolución, en lugar de explicitar directamente las razones de su elección, remite a otro documento: es una técnica de integración del texto lingüístico, utilizado incluso por el legislador». El autor dice que tal forma de motivación puede ser

${ }^{84}$ NAPpI (1992), pp. 119-127.

${ }^{85}$ FolLieri (2008), pp. 495-497. 
legítima en la medida que se haga remisión a un texto «que sea un legítimo acto del procedimiento y sea conocido o susceptible de ser conocido por el interesado, (...) y que la decisión del juez no se presente como una acrítica aceptación de precedentes valoraciones, con el fin de evitar que constituya un sustancial vaciamiento del medio de impugnación ${ }^{86}$.

Sobre todo el último elemento, es decir, la acrítica aceptación de las valoraciones precedentes, convierte a la motivación en un acto puramente formal y estereotipado, a través del cual se elude dar cuenta de las específicas alegaciones contenidas en el recurso contra la resolución que se impugna, sin argumentar acerca de la inconsistencia o la impertinencia de dichos motivos. Desde luego una utilización de este tipo no constituye una forma admisible de motivación per relationem ${ }^{87}$. La jurisprudencia sobre recursos producida en nuestro medio suele, sin embargo, incurrir en estos vicios, circunstancia que reviste especial gravedad en un sistema de impugnación con recurso único como es el chileno: únicamente recurso de nulidad (para las sentencias dictadas en juicios orales), lo cual deja a las partes en la absoluta imposibilidad de reclamar de estos vicios procesales, esfumándose el derecho al recurso como manifestación jurisdiccional ${ }^{88}$.

El CPP chileno (y su concreta aplicación jurisprudencial imperante) viene a padecer de una grave incoherencia, pues de una parte el legislador ha previsto una rigurosísima regla de motivación fáctica y jurídica en el art. 297 CPP, y ha proclamado unas reglas de valoración explícitas, aunque inconvenientemente genéricas, y no obstante toda esa pretendida rigurosidad del legislador se ha visto frustrada por la escasísima apertura recursiva de controles adecuados tanto respecto de la calidad de la motivación como de la corrección del juicio de valoración de los medios de prueba para la fijación del juicio fáctico. Con lo anterior se deriva a un sistema que sólo proclama pero no asegura o garantiza la motivación y la correcta valoración de la prueba, y que de alguna manera acaba dejando en la ineficacia una de las finalidades mismas de la motivación tan bien puesta de relieve por CALAMANDRE ${ }^{89}$, cuando apuntaba que uno de sus propósitos es la de hacer posible la impugnación de las mismas ${ }^{90}$.

\footnotetext{
86 Traducción nuestra.

${ }^{87}$ Vid. Follieri (2008), pp. 495-497.

${ }^{88}$ Vid. Ferrajoli (1992), pp. 29-41.

89 Vid. Calamandrei (2006), pp. 101-109.

${ }^{90}$ Nótese que Nuzzo (2008), p. 24, cree que este fin endoprocesal de la motivación, constitucionalmente consagrado (art. 111.6 Const. italiana) puede ser un argumento a favor del respaldo constitucional del recurso de apelación.
} 
Pero el problema que enfrentamos nosotros es en la dirección inversa: pues buena o mala motivación o valoración da igual, da igual la pretendida estrictez del legislador sobre estas cuestiones, ya que no existe cauce expedito para verificar o controlar dichas circunstancias.

b) El problema de un procedimiento que no asegura vías de alegación y conocimiento adecuadas

En fin, si se analiza con detenimiento la regulación de los recursos y, en especial, del recurso de nulidad se observará que el régimen establecido resulta en la práctica muy restrictivo, lo cual es derechamente criticable en un sistema de recurso único contra la decisión de fondo. Así, por ejemplo, se dispone un plazo para la interposición brevísimo de 10 días corridos (mucho más breve que el existente en otros modelos, que establecen términos más generosos incluso para la casación), que afecta la calidad de los recursos o incluso a veces la misma decisión de recurrir.

Por otra parte, también resulta preocupante que el mismo conocimiento del Tribunal ad quem aparezca en la práctica poco estimulado por el sistema en su conjunto. Piénsese, por ejemplo, en la forma de registro del juicio oral, a través de la grabación únicamente de audio, y no audiovisual ${ }^{91}$, lo cual incide como un natural desincentivo del escrupuloso y exhaustivo examen de los mismos, que en no pocas ocasiones es menester para pronunciarse con conocimiento sobre un vicio en el razonamiento probatorio, o respecto de un vicio procesal o infracción de garantía procesal. No se prevé norma legal alguna que asegure o exija al Tribunal ad quem imponerse del contenido del registro durante la vista de los recursos o que permita a las partes provocar durante la vista el examen del registro.

\section{BibLIOGRAFíA}

ACCATINO, Daniela (2009): «Forma y sustancia en el razonamiento probatorio. El alcance del control sobre la valoración de la prueba a través del recurso de nulidad penal», en Revista de Derecho, PUCV (XXXII, 2009-I), pp. 347-362.

- (2010): «El modelo legal de justificación de los enunciados probatorios en las sentencias penales y su control a través del recurso de nulidad», en AAVV,

\footnotetext{
${ }^{91}$ Aquí parece tan pertinente lo que decía hace más de 130 años el mismo WACH (2006), p. 258, acerca de la apelación en un sistema con oralidad e inmediación y la posibilidad de que ésta pueda convertirse en el medio para hacer prevalecer el juicio del juez más mal informado, el ad quem, por sobre el del mejor informado, el a quo, cuando matiza inmediatamente que aquello sólo se produce en determinadas y específicas circunstancias, poniendo de relieve entre otras la importancia de los registros o actas del juicio (su calidad) para asegurar una buena calidad del conocimiento.
} 
Formación y valoración de la prueba en el proceso penal (Coordinadora Accatino), pp. 119-143.

Barrientos Pardo, Ignacio (2007): «Prohibición de la reformatio in peius y la realización de nuevo juicio», en Revista de estudios de la Justicia (2007, No 9), pp. 175-207.

Bonnet, Piero Antonio (2000): «Il giudizio matrimoniale al cospetto del terzo millenio", en AAVV, Hominum causa omne ius constitutum est (coordinadores Castán Vázquez, Guzmán Pérez, Pérez-Agua López y Sánchez García, Madrid, Universidad Pontificia de Comillas).

Bordalí Salamanca, Andrés (2003): «El debido proceso civil», en AAVV, La constitucionalización del Derecho chileno (Santiago, Editorial Jurídica de Chile), pp. 251-295.

Calamandrei, Piero (1945a): La casación civil, T. I, V. I (traducción de Sentís Melendo, Buenos Aires, Editorial Bibliográfica de Argentina).

(1945b): La casación civil, T. I, V. II, (traducción de Sentís Melendo, Argentina, Editioral Bibliográfica de Argentina).

(1945c): La casación civil, T. II, V. III, (traducción de Sentís Melendo, Buenos Aires, Editoral Bibliográfica de Argentina).

(2006): Proceso y democracia (traducción de Fix-Zamudio, Perú, Ara Editores). Calderón Cuadrado, María Pía (2005): La segunda instancia penal (Cizur Menor, España, Thomson Aranzadi).

CAPPA, Alessandra (2004): «Profili problematici della revisione della sentenza 'patteggiata'”, en DE CARO, Agostino (a cura), Patteggiamento allargato e sistema penale (Milano, Giuffrè,), pp. 153-178.

CARocca Pérez, Álex (2000): «Recursos en el nuevo sistema procesal penal» en AAVV, Nuevo proceso penal (Santiago, Editorial Conosur), pp. 297-331.

- (2003): El nuevo sistema procesal penal (Santiago, Editorial Jurídica La Ley).

Cecanese, Gianfederico (2004): «Natura della sentenza che applica la pena e procedimento disciplinare», en DE CARO, Agostino (a cura), Patteggiamento allargato e sistema penale (Milano, Giuffrè), pp. 127-152.

Cortez Matcovich, Gonzalo (2006): El recurso de nulidad (Santiago, LexisNexis).

COLOMA CORREA, Rodrigo (2005): «Panorama general de la prueba», en AAVV, La prueba en el nuevo proceso penal oral (Santiago, LexisNexis), pp. 5-34.

- Et al. (2009): «Fundamentación de sentencias judiciales y atribución de calidad epistémica a las declaraciones de testigos en materia procesal penal», en 
Revista de Derecho de la Pontificia Universidad Católica de Valparaíso (2009-2, No 33), pp. 303-344.

DAMAŠKA, Mirjan (2000): Las caras de la justicia y el poder del Estado. Análisis comparado del proceso legal (traducción castellana de Morales VIDAL, Andrea, Santiago, Editorial Jurídica de Chile).

- (2003): Il diritto delle prove alla deriva (traducción italiana de CuOmo UlloA, Francesca y RIVA, Valentina, Bologna, Il Mulino).

De CARO, Agostino (2004): «Le linee politiche della legge n. 134 del 2003, principi fondamentali e nuovo 'patteggiamento'", en él mismo (a cura), Patteggiamento allargato e sistema penale (Milano, Giuffrè), pp. 1-33.

Del Río Ferretti, Carlos (2007): La correlación de la sentencia con la acusación y la defensa. Estudio comparado del derecho español con el chileno (Servicio de publicaciones de la Universidad de Valencia, 2007).

- (2008): «El principio del consenso de las partes en el proceso penal y enjuiciamiento jurisdiccional: aclaraciones conceptuales necesarias», en Revista chilena de derecho (2008, vol. 35-1), pp. 157-182.

- (2009): Proceso penal, consenso de las partes y enjuiciamiento jurisdiccional (Santiago, Librotecnia).

- (2009): Los poderes de decisión del juez penal. Principio acusatorio y determinadas garantías procesales (Santiago, Editorial Jurídica de Chile, 2009).

De Rosa, Damiano (2004): «La diferente tipologia delle sentenze 'di patteggiamento e i nuovi effetti premiali connessi alle specifiche forme procedurali'», en De Caro, Agostino (a cura), Patteggiamento allargato e sistema penale (Milano, Giuffrè), pp. 87-125.

De Roberto, Giovanni (2008): en AAVV, Codice di Procedura Penale (Milano, Giuffrè), pp. 55-257.

Di Luciano, Flavia (2009): L'appello Penale (Torino, Giappichelli Editore).

Duce Julio, Mauricio y Riego Ramírez, Cristián (2007): Proceso penal (Editorial Jurídica de Chile).

Evans DE LA CuAdra, Enrique (2004): Los derechos constitucionales, tomo II, segunda edición (Editorial Jurídica de Chile).

FERNÁNDEZ GonZÁLEZ, Miguel Ángel (2005): «La apelación en el nuevo proceso penal frente al derecho constitucional», en Revista de Derecho Público (2005, volumen 67), pp. 145-169.

- (2006): La nueva justicia penal (Santiago, Editorial LexisNexis). 
- (2008): «El recurso de nulidad en el Código Procesal Penal desde la perspectiva de la Constitución", en Revista de Derecho de la Universidad Católica del Norte (2008, No 15-1), pp. 91-114.

FERRAJOLI, Luigi (1992): «I valori del doppio grado e della nomofilachia», en AAVV, Il giudizio di cassazione nel sistema delle impugnazioni (a cura di MANNUZZU y Sestini, Roma, Edizione Tritone), pp. 29-41.

- (1995): Derecho y razón. Teoría del garantismo penal (traducción castellana de Andrés Ibáñez, Ruiz Miguel, Bayón Mohíno, Terradillos Basoco, Cantarero Bandrés, Madrid, Trotta, 1995).

- (2004): El derecho como sistema de garantías, en Derecho y garantías. La ley del más débil, cuarta edición (traducción castellana Andrés IbáÑzZ, Perfecto y GREPPI, Andrea, Madrid, Trotta), pp. 15-35.

- (2007a): Principia Iuris. Teoria del diritto e della democrazia, I (teoria del diritto) (Roma-Bari, Laterza).

- (2007b): Principia Iuris. Teoria del diritto e della democrazia, II (teoria della democrazia) (Roma-Bari, Laterza).

FERRER BELTRÁn, Jordi (2007): La valoración racional de la prueba (Madrid-Barcelona-Buenos Aires, Marcial Pons).

FErrua, Paolo (1992): «Il sindacato di legittimità sul vizio di motivazione dei provvedimenti penali», en AAVV, Il giudizio di cassazione nel sistema delle impugnazioni (a cura di MANnuZZU y Sestini, Roma, Edizione Tritone), pp. 83-98.

FleTCHER, George (2004): Grammatica del diritto penale (traducción al italiano de PAPA, Michele, Bologna, Il Mulino).

Follieri, Antonella (2008): en AAVV, Codice di Procedura Penale (Milano, Giuffrè), pp. 461-559.

Gascón Abellán, Marina (1999): Los hechos en el derecho. Bases argumentales de la prueba (Madrid-Barcelona, Marcial Pons).

Gössel, Karl-Heinz (2004): El proceso penal ante el Estado de Derecho. Estudios sobre el Ministerio Público y la prueba penal (traducción al español de POLAINo Navarrete, Miguel, Lima, Grijley).

Horvitz Lennon, María Inés (2009): «Acerca de la garantía del condenado de recurrir en contra de la sentencia condenatoria», en Informes en Derecho. Doctrina procesal penal 2008 (No 6, 2009), pp. 9-25.

IlluminaTI, Giulio (1988): «Accusatorio ed inquisitorio (sistema)», en Enciclopedia Giuridica, Istituto della enciclopedia italiana, tomo I (1988, Roma). 
López Masle, Julián (con Horvitz Lennon) (2005): Derecho procesal penal, tomo II, (Editorial Jurídica de Chile).

- (2007): «Informe en Derecho sobre la Prohibición de la 'reformatio in peius' y la nulidad parcial de las sentencias en el procedimiento penal» (Santiago, 10 de diciembre de 2007), 34 pp.

MAIER, Julio (1989): Derecho procesal penal argentino, tomo 1b, segunda edición (Buenos Aires, Argentina, Hammurabi).

MarColini, Stefano (2005): Il patteggiamento nel sistema della giustizia penale negoziata (Milano, Giuffrè).

Montero Aroca, Juan (1997): Principios del proceso penal (Valencia, Tirant lo Blanch)

- Et al. (2005): Derecho Jurisdiccional, II, Proceso Civil, décimo cuarta edición (Valencia, Tirant lo Blanch).

NAPrI, Aniello (1992): Un’ipotesi di modifica del giudizio penale d'appello, en AAVV, Il giudizio di cassazione nel sistema delle impugnazioni (a cura di MANNUZZU y Sestini, Roma, Edizione Tritone), pp. 119-127.

Nogueira Alcalá, Humberto (2007): El debido proceso en la Constitución y el sistema interamericano (Santiago, Librotecnia).

Nuzzo, Franceso (2008): L'appello nel processo penale, terza edizione (Milano, Giuffrè).

Ortells Ramos, Manuel et al. (1998): Derecho Jurisdiccional, III, Proceso Penal, séptima edición (Valencia, Tirant lo Blanch).

- Et al. (2009): Derecho procesal civil, novena edición (Cizur Menor, AranzadiWestlaw).

Pastor, Daniel (2001): La nueva imagen de la casación penal (Buenos Aires, Ad Hoc, 2001).

Pereira Anabalón, Hugo (1999): «Oralidad e instancia única o doble en el proceso penal», en Gaceta Jurídica (1999, № 233), pp. 15-21.

- (2005): «Legitimidad del Ministerio Público para interponer recurso de nulidad en el proceso penal», en Gaceta Jurídica (2005, No 306), pp. 41-46.

Riccio, Giuseppe (2008): «Presentazione», en L'appello nel processo penale, terza edizione, Nuzzo, F. (Milano, Giuffrè), pp. V-XIII.

Rieutord Alvarado, Andrés (2007): El recurso de nulidad en el nuevo proceso penal (Editorial Jurídica de Chile).

Roxin, Claus (2000): Derecho procesal penal (traducción de CÓRDOBA, Gabriela y PAsTor, Daniel, Buenos Aires, Editores del Puerto). 
Ruggiero, Andrea (2004): «Forme di patteggiamento. Dal patto sulla sanzione alla conciliazione sul fatto: un obbietivo nuovamente mancato", en DE CARO, Agostino (a cura), Patteggiamento allargato e sistema penale (Milano, Giuffrè), pp. 35-86.

Santalucia, Giuseppe (2008): en AAVV, Codice di Procedura Penale (Milano, Giuffrè), pp. 1-55.

Silva Bascuñán, Alejandro (2002): Tratado de derecho constitucional, tomo VIII (Editorial Jurídica de Chile).

SCHÜNEMANN, Bernd (2002): «¿Crisis del procedimiento penal? ¿Marcha triunfal del procedimiento americano en el mundo?», en Temas actuales y permanentes del Derecho penal después del milenio (traducción de BaCigalupo, Silvina y BAZA, Lourdes, Madrid, Tecnos), pp. 288-302.

- (2005): La reforma del proceso penal (traducción de SACHER, Mariana, Madrid, Cuadernos 'Luis Jiménez de Asúa', Dykinson).

TARUfFo, Michele (2005a): Vértice ambiguo. Ensayos sobre la casación civil (traducción castellana de Monroy Palacios, Juan y Monroy Gálvez, Juan, Lima-Perú, Palestra).

- (2005b): La prueba de los hechos, segunda edición (traducción castellana de Ferrer Beltrán, Jordi, Madrid, Trotta).

- (2008): La prueba (traducción castellana de Manríquez, Laura y Ferrer Beltrán, Jordi, Madrid-Barcelona-Buenos Aires, Marcial Pons).

- (2008): «¿Verdad negociada?», ahora, en él mismo, La prueba (MadridBarcelona-Buenos Aires, Marcial Pons), pp 229-249.

- (2009): «Consideraciones sobre prueba y motivación", en Consideraciones sobre la prueba judicial (traducción castellana de Andrés IBÁÑEZ, Perfecto, Madrid, Fundación Coloquio Jurídico Europeo), pp. 17-46.

TAPIA FERnÁNDEZ, Isabel et al. (2005): El proceso penal en la doctrina del Tribunal Constitucional (Cizur Menor, Aranzadi), pp. 1091-1183.

Tavolari Oliveros, Raúl (2005): «¿Tiene el Ministerio Público derecho a un debido proceso?, en Instituciones del nuevo proceso penal (Editorial Jurídica de Chile), pp. 260-269.

- (2005): «De los recursos en el nuevo Código Procesal Penal», en Revista de Derecho procesal (2005, No 20), pp. 393-409.

Tonini, Paolo (2007): Manuale di procedura penale, ottava edizione (Milano, Giuffrè).

TwInING, William (2006): «What is the Law Evidence?», en Rethinking Evidence. Exploratory Essays, Segunda edición (Cambridge University Press), pp. $192-$ 236. 
WACH, Adolf (2006): Conferencias sobre la Ordenanza procesal civil alemana (traducción de Krotoschin, Ernesto, Ara Editores, Lima, Perú).

WróbleWSKI, Jerzy (1979): «Facts in Law», ahora en AARNIO, Aulius (Editor), en Meaning and Truth in Judicial Decision (Helsinki, Juridica), pp. 113-139.

(1979): «The problem of the so-called judicial truth», ahora en AArNio, Aulius (Editor), Meaning and Truth in Judicial Decision (Helsinki, Juridica), pp. 166-188.

(1992): The Judicial Application of Law (Dordrecht, Netherlands, Kluwer).

\section{JURISPRUDENCIA CHILENA CITADA ORDENADA POR ÓRGANO Tribunal Constitucional}

Rol 986-2007: Tribunal Constitucional de Chile, de 30 de enero de 2008, en http://www.tribunalconstitucional.cl/wp/descargar_sentencia.php?id=730.

Rol 821-07-INA: Tribunal Constitucional de Chile, de 1 de abril de 2008, en http://www.tribunalconstitucional.cl/wp/descargar_sentencia.php?id=902.

Rol 1130-07-INA: Tribunal Constitucional de Chile, de 7 de octubre de 2008, en http://www.tribunalconstitucional.cl/wp/descargar_sentencia.php?id=1023.

\section{Corte Suprema}

Ministerio Público con Inostroza Barrera (2005): Corte Suprema de 15 de noviembre de 2005, rol 3984-05, en Base de datos Legal Publishing, No Identificación 33196.

Ministerio Público con Rodríguez Fuentealba y otros (2005): Corte Suprema de 30 de noviembre de 2005, rol 4656-05, en Base de datos Legal Publishing, No Identificación 33244.

Ministerio Público con Cádiz Figueroa y otros (2006): Corte Suprema de 15 de febrero de 2006, rol 267-2006, en Base de datos Legal Publishing, No Identificación 33808.

Ministerio Público con Muñoz Figueroa (2006): Corte Suprema de 30 de enero de 2007, rol 6583-2006, Base de datos Legal Publishing, No Identificación 35949.

Ministerio Público con Cabello Roblero (2007): Corte Suprema de 22 de mayo de 2007, rol 1300-07, en Base de datos Legal Publishing, No Identificación 36478.

Ministerio Público con Lagos Rosales (2008): Corte Suprema de 8 de abril de 2008, rol 1304-08, en Base de datos Legal Publishing No Identificación 38720. 
Ministerio Público con Samaha Silva (2008): Corte Suprema de 26 de mayo de 2008, rol 2055-2008, en Base de datos Legal Publishing No Identificación 39049.

Ministerio Público con Faúndez Pinilla (2009): Corte Suprema de 25 de marzo de 2009, rol 1239-09, http://www.pjud.cl/modulos/BusqCausas/BCA_estado_causa_nuevo.php

Ministerio Público con Fernández Sarmientos y otros (2010): Corte Suprema de 12 de julio de 2010, rol 3003-10, en Base de datos Legal Publishing, No Identificación 45268.

\section{Corte de apelaciones}

Ministerio Público con Moy Plaza (2008): Corte de Apelaciones de Antofagasta de 11 de junio de 2008, rol 103-2008, en Base de datos Legal Publishing No Identificación 39211.

Ministerio Público con Huerta Durán (2008), Corte de Apelaciones de Temuco de 17 de noviembre de 2008, rol 1113-2008, en http://www.pjud.cl/modulos/ BusqCausas/BCA_esta402.php?rowdetalle=AAANoPAAOAABmm0AAC $\&$ consulta $=100 \&$ causa $=1113 / 2008 \&$ numcua $=27017 \&$ secre $=$ REFORMA PROCESAL PENAL

Ministerio Público con Rivero Paz y otros (2008): Corte de Apelaciones de Antofagasta de 17 de diciembre de 2008, rol 274-2008.

Ministerio Público con Campaña Munizaga (2011): Corte de Apelaciones de La Serena de 24 de agosto de 2011, rol 203-2011.

\section{JuRisprudenCia de Órganos Internacionales \\ Comité de derechos humanos de la $O N U$}

Gómez Vásquez c. España, 701/1996: Comité de derechos humanos de la ONU, Dictamen de 20 de junio de 2000.

Joseph Semey c. España, 986/2001: Comité de derechos humanos de la ONU, Dictamen de 30 de julio de 2003.

Sineiro Fernández c. España, 1007/2001: Comité de derechos humanos de la ONU,

Dictamen de 7 de agosto de 2003.

Alba Cabriada c. España, 1101/2002: Comité de derechos humanos de la ONU, Dictamen de 1 de noviembre de 2004.

Martínez Fernández c. España, 1104/2002: Comité de derechos humanos de la ONU, Dictamen de 29 de marzo de 2005. 


\section{Corte Interamericana de derechos humanos}

Castillo Petruzzi y otros v/s Perú: Corte Interamericana de derechos Humanos, Sentencia de 30 de mayo de 1999.

Herrera Ulloa vs. Costa Rica: Corte Interamericana de derechos humanos, Sentencia de 2 de julio de 2004. 
